\title{
MHD squeeze flow and heat transfer of a nanofluid between parallel disks with variable fluid properties and transpiration
}

\author{
K. Vajravelu ${ }^{1 *}$, K. V. Prasad ${ }^{2}$, Chiu-On $\mathrm{Ng}^{3}$ and Hanumesh Vaidya ${ }^{2}$
}

\begin{abstract}
Background: The purpose of the study is to investigate the effects of variable fluid properties, the velocity slip and the temperature slip on the time-dependent MHD squeezing flow of nanofluids between two parallel disks with transpiration.

Methods: The boundary layer approximation and the small magnetic Reynolds number assumptions are used. The non-linear governing equations with appropriate boundary conditions are initially cast into dimensionless form by using similarity transformations and then the resulting equations are solved analytically via Optimal Homotopy Analysis Method (OHAM). A detailed parametric analysis is carried out through plots and tables to explore the effects of various physical parameters on the velocity temperature and nanoparticles concentration fields.

Results: The velocity distribution profiles for transpiration (suction/blowing) are parabolic in nature. In general, at the central region, these profiles exhibit the cross-flow behavior and also exhibit the dual behavior with the increase in the pertinent parameters. The temperature distribution reduces in the case of suction whereas the reverse trend is observed in the case of injection.

Conclusion: The effects of temperature dependent thermophysical properties are significant on the flow field. For higher values of the fluid viscosity parameter, the velocity field increases near the walls. However, the transpiration effects are dominant and exhibit the cross-flow behavior as well as the dual behavior. The temperature and the concentration fields are respectively the increasing functions of the variable thermal conductivity and the variable species diffusivity parameters.
\end{abstract}

Keywords: Squeeze flow, Nanofluid, Wall slip, OHAM, Transpiration

\section{Background}

Squeeze flow has promising applications in engineering and industrial processes such as bio-mechanics, flow through arteries, food processing, polymer processing, compression, injection modeling, and mechanical, industrial, and chemical engineering. Generally, squeeze flows are generated in many hydro-dynamical machines and tools where vertical velocities or normal stresses are applied due to moving boundary. Stefan (1874) initiated the study by considering the squeeze flow of a Newtonian fluid with lubrication approximation. Leider and Bird (1974) and Hamza (1988) extended the pioneering work of Stefan (1874) for flow between two parallel disks. Domairry and Aziz (2009) performed a comprehensive

\footnotetext{
* Correspondence: kuppalapalle.vajravelu@ucf.edu

${ }^{1}$ Department of Mathematics, University of Central Florida, Orlando, FL 32816, USA

Full list of author information is available at the end of the article
}

analysis of an electrically conducting fluid between two parallel disks of which the upper disk is impermeable and the lower disk is permeable. Joneidi et al. (2010) analyzed the effects of suction/injection and squeeze Reynolds number on the magnetohydrodynamic flow between two parallel disks. Hayat et al. (2012) extended the work of Domairry and Aziz (2009) to second-grade fluid using HAM homotopy analysis method. Further, Hussain et al. (2012) examined the unsteady MHD flow and heat transfer of a viscous fluid squeezed between two parallel disks. Furthermore, Shaban et al. (2013) reported the time-dependent squeeze MHD flow between two parallel disks via a new hybrid method based on the Tau method and the homotopy analysis method.

In recent years, manufacturing industries have begun to choose the fluids based on the heat transmission property: This has considerable implications in the performance of many devices such as in air-conditioning, electronic, 
chemical, and power. The traditional fluids such as water, ethylene glycol, mineral oils have limited heat transfer ability. Choi (1995) coined the word "nanofluid" for the fluids with suspended nanometer sized $\left(10^{-9} \mathrm{~nm}\right)$ particles called nanoparticles, which were dispersed in traditional fluids. The distinctive nature of the nanofluid, higher thermal conductivity at low nanoparticle aggregation, strong temperature-dependent thermal conductivity, and nonlinear increase in thermal conductivities are more useful in industrial and engineering applications which include nuclear reaction cooling, geothermal power extraction, automobile fuels, radiator cooling, cooling of electronic devices, smart fluids, and in bio- and pharmaceutical industry. Motivated by the aforementioned applications, numerous researchers have engaged in the discussion of flows of nanofluids through different geometries (see Vajravelu et al. 2011; Makinde and Aziz 2011; Bachok et al. 2012; Safaei et al. 2014; Safaei et al. 2014; Goodarzi et al. 2014; Togun et al. 2014; Prasad et al. 2016). The MHD squeezing flow of nanofluid between parallel disks is studied by Hashmi et al. (2012). Recently, Das et al. (2016) presented a numerical study on the squeeze flow of a nanofluid between two parallel disks in the presence of a magnetic field considering slip effects. Mohyud-Din et al. (2016) considered both velocity and temperature slip effects on squeeze MHD flow of a nanofluid between parallel disks.

All the above studies analyzed the characteristics of nanofluid squeeze flows assuming constant thermo-physical properties. However, several researchers (see Lai and Kulacki (1990), Vajravelu et al. (2013), Prasad et al. (2016)) have shown that the thermo-physical properties of the ambient fluid may change with temperature, especially the fluid viscosity and the fluid thermal conductivity. For lubricating fluids, heat generated by internal friction and the corresponding rise in the temperature affects the physical properties of the nanofluid, and hence the properties of the fluid are no longer assumed to be constant. The increase in temperature leads to an increase in the transport phenomena and so the heat transfer at the wall is also affected. The experimental results show that even a very low volume fraction of nanoparticles can significantly affect the thermo-physical properties of a nanofluid (see Vajjha and Das (2012)). Therefore, to predict the flow, heat, and mass transfer rates, it is necessary to take the variable fluid properties into account. Thus, the purpose here is to investigate the effects of variable fluid properties, the velocity slip, and the temperature slip on the time-dependent MHD squeezing flow of nanofluids between two parallel disks with transpiration. The governing partial differential equations are transformed into a set of ordinary differential equations: The non-linear coupled systems of equations have been solved for various values of sundry parameters via an efficient analytical method, optimal homotopy analysis method (OHAM) (for details see Liao (2003), Fan and You (2013)). The analysis revels that the fluid flow is appreciably influenced by the physical parameters. It is expected that the results presented here will not only provide useful information for industrial applications but also complement the existing literature.

\section{Mathematical formulation}

Let us consider the MHD incompressible flow of an electrically conducting nanofluid squeezed between two parallel disks separated by a variable distance $h(t)=H(1-\alpha t)^{1 / 2}$ where $\alpha$ is a parameter having the dimension of inverse time. The upper disk at $z=h(t)$ is moving with the velocity $d z / d t=-(1 / 2)(\alpha H / \sqrt{(1-\alpha t)})$ towards or away from the stationary lower disk at $z=0$. Mathematically, $w=\partial h / \partial t$ represents squeezing of the upper disk with the lower disk. The axial coordinate is denoted by $z$ and the radial coordinate by r. $u$ and $w$ are the radial and axial velocities, respectively. A magnetic field of strength $B(t)=B_{0}(1-\alpha t)^{-1 / 2}$ is applied

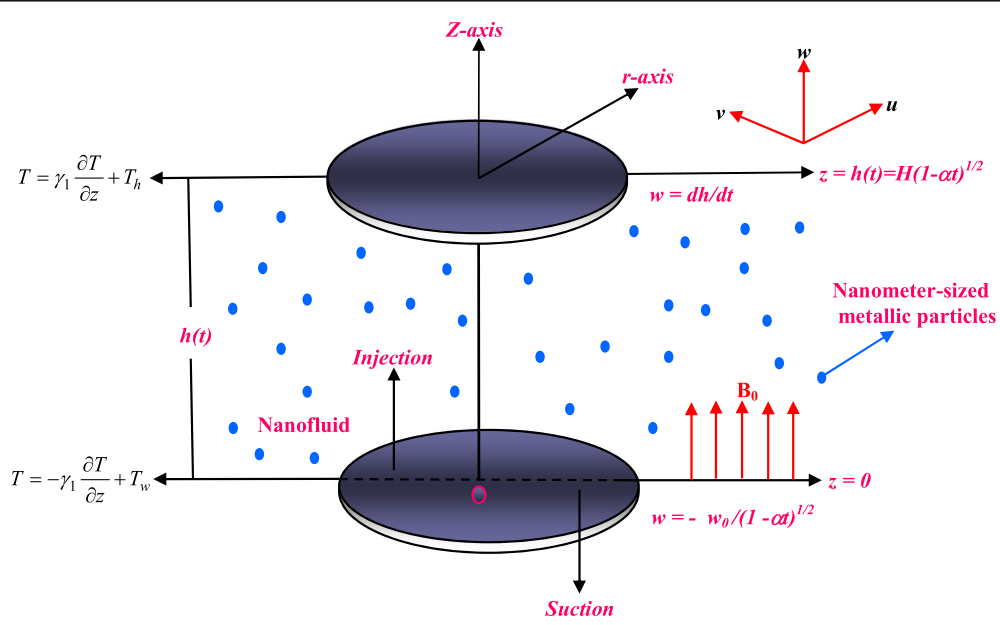

Fig. 1 Geometry of the problem 
perpendicular to the disks. On the basis of low Reynolds number assumption, the induced magnetic field is neglected. Here, $T_{w}$ and $C_{w}$ denote the temperature and nanoparticles concentration at the lower disk while the temperature and concentration at the upper disk are $T_{h}$ and $C_{h}$, respectively. The physical configuration is represented in Fig. 1. Here, the cylindrical polar coordinates are chosen for the system. Due to the rotational symmetry of the flow, the azimuthal component of the velocity vanishes identically. Under these assumptions, the governing equations for unsteady twodimensional flow and heat transfer of a viscous nanofluid are (see Hashmi et al. (2012) and Das et al. (2016)):

$$
\begin{aligned}
\frac{\partial u}{\partial r}+\frac{u}{r}+\frac{\partial w}{\partial z}= & 0 \\
\frac{\partial u}{\partial t}+u \frac{\partial u}{\partial r}+w \frac{\partial u}{\partial z}= & -\frac{1}{\rho_{f}} \frac{\partial p}{\partial r}+\frac{1}{\rho_{f}}\left(\begin{array}{l}
\frac{\partial}{\partial r}\left(\mu(T) \frac{\partial u}{\partial r}\right)+\frac{\partial}{\partial z}\left(\mu(T) \frac{\partial u}{\partial z}\right) \\
+\mu(T)\left(\frac{1}{r} \frac{\partial u}{\partial r}-\frac{u}{r^{2}}\right)
\end{array}\right) \\
& -\frac{\sigma B_{0}^{2}(t)}{\rho_{f}} u,
\end{aligned}
$$$$
\frac{\partial w}{\partial t}+u \frac{\partial w}{\partial r}+w \frac{\partial w}{\partial z}=-\frac{1}{\rho_{f}} \frac{\partial p}{\partial z}
$$$$
+\frac{1}{\rho_{f}}\left(\frac{\partial}{\partial r}\left(\mu(T) \frac{\partial w}{\partial r}\right)+\frac{\mu(T)}{r} \frac{\partial w}{\partial r}+\frac{\partial}{\partial z}\left(\mu(T) \frac{\partial w}{\partial z}\right)\right),
$$

$$
\begin{aligned}
\frac{\partial T}{\partial t}+u \frac{\partial T}{\partial r}+w \frac{\partial T}{\partial z}= & \frac{1}{\rho_{f} C_{p}}\left(\begin{array}{l}
\frac{\partial}{\partial r}\left(\lambda(T) \frac{\partial T}{\partial r}\right)+\frac{\partial}{\partial z}\left(\lambda(T) \frac{\partial T}{\partial z}\right) \\
+\lambda(T) \frac{1}{r} \frac{\partial T}{\partial r}
\end{array}\right) \\
+\tau & {\left[\begin{array}{l}
D_{B}(C)\left(\frac{\partial C}{\partial r} \frac{\partial T}{\partial r}+\frac{\partial C}{\partial z} \frac{\partial T}{\partial z}\right) \\
+\frac{D_{T}}{T_{m}}\left\{\left(\frac{\partial T}{\partial r}\right)^{2}+\left(\frac{\partial T}{\partial z}\right)^{2}\right\}
\end{array}\right], }
\end{aligned}
$$$$
\begin{aligned}
\frac{\partial C}{\partial t}+u \frac{\partial C}{\partial r}+w \frac{\partial C}{\partial z}= & \left(\begin{array}{l}
\frac{\partial}{\partial r}\left(D_{B}(C) \frac{\partial C}{\partial r}\right)+\frac{D_{B}(C)}{r} \frac{\partial C}{\partial r} \\
+\frac{\partial}{\partial z}\left(D_{B}(C) \frac{\partial C}{\partial z}\right)
\end{array}\right) \\
& +\frac{D_{T}}{T_{m}}\left\{\frac{\partial^{2} T}{\partial z^{2}}+\frac{\partial^{2} T}{\partial r^{2}}+\frac{1}{r} \frac{\partial T}{\partial r}\right\}
\end{aligned}
$$

Here, $\rho_{f}$ is the density of the fluid, $\sigma$ is the electric conductivity, $T$ is the temperature of the fluid, and $C$ is the nanoparticle concentration. Further, $\mu$ is the coefficient of viscosity which is considered to vary as an inverse function of temperature (see Lai and Kulacki (1990), Vajravelu et al. (2013), Prasad et al. (2016)) as

$$
\begin{aligned}
\mu & =\frac{\mu_{h}}{\left[1+\zeta\left(T-T_{h}\right)\right]} \quad \text { i.e., } \quad \frac{1}{\mu} \\
& =a\left(T-T_{r}\right), \text { where } a=\frac{\zeta}{\mu_{h}} \text { and } T_{r} \\
& =T_{h^{-}} \frac{1}{\zeta} .
\end{aligned}
$$

Here, both $a$ and $T_{r}$ are constants, and their values depend on the reference state and the parameter $\zeta$, reflecting a thermal property of the fluid. In general, $a>0$ corresponds to liquid and $a<0$ to gasses. Also, let $\theta_{r}$ be the constant which is defined by $\theta_{r}=\left(T_{r}-T_{h}\right) / \Delta T=-1 /(\zeta \Delta T)$, where $\Delta T=\left(T_{w}-\right.$ $\left.T_{h}\right)$. It is worth mentioning here that for $\zeta \rightarrow 0$ i. e., $\mu=\mu_{h}$ (constant), $\theta_{r} \rightarrow \infty$. It is also important to note that $\theta_{r}$ is negative for liquids and positive for gasses. This is due to the fact that viscosity of a liquid usually decreases with increasing temperature while it increases for gasses. The temperature-dependent thermal conductivity $\lambda(T)$ and the species dependence on molecular diffusion of the diffusing species $D_{B}(C)$ (diffusion coefficient) in the fluid are assumed to vary as linear functions of temperature and nanoparticle species diffusion respectively in the following forms:

$$
\begin{aligned}
\frac{1}{\rho_{h} C_{p}} \lambda(T)= & \lambda_{h}\left(=\frac{k_{h}}{\rho_{h} C_{p}}\right) \\
& \times\left(1+\varepsilon_{1}\left(\frac{T-T_{h}}{T_{w}-T_{h}}\right)\right) \text { and } D_{B}(C) \\
= & D_{B h}\left(1+\varepsilon_{2}\left(\frac{C-C_{h}}{C_{w}-C_{h}}\right)\right),
\end{aligned}
$$

where $\varepsilon_{1}$ and $\varepsilon_{2}$ are the small parameters, respectively, called variable thermal conductivity parameter and the variable species diffusivity parameter. $T_{w}$ and $C_{w}$ are the temperature and the nanoparticle concentration at the lower disk whereas $\mu_{h}, k_{h}$, and $D_{\mathrm{Bh}}$ are respectively the fluid viscosity, thermal conductivity, and the species diffusivity/Brownian diffusion coefficient of the fluid at the upper disk, $T_{m}$ is the mean fluid temperature, $D_{T}$ is the thermophoretic diffusion coefficient, $\tau=\left(\rho_{\infty} c_{p}\right)_{p} /\left(\rho_{\infty} c_{p}\right)_{f}$ is the ratio between the effective heat capacity of the nanoparticle material and heat capacity of the fluid. Thus, the value of $\tau$ will be therefore different for different fluids and nanoparticle materials. The appropriate boundary conditions for the problem (see Das et al. (2016)) are

$$
\begin{aligned}
u=-\beta_{i} \frac{\partial u}{\partial z}, w & =-\frac{w_{0}}{\sqrt{1-\alpha t}}, T=-\gamma_{1} \frac{\partial T}{\partial z}+T_{w}, \\
C & =C_{w} \text { at } z=0, \\
u=\beta_{i} \frac{\partial u}{\partial z}, w & =w_{h}\left(=\frac{d h}{d t}\right), T=\gamma_{1} \frac{\partial T}{\partial z}+T_{h}, \\
C= & C_{h} \text { at } z=h(t)
\end{aligned}
$$


where $\beta_{1}$ is the velocity slip parameter and $\gamma_{1}$ is the thermal slip parameter.

\section{Similarity equations for nanofluid model}

For the physical model considered, it is observed that the nanoparticle species diffusion and thermal and momentum boundary layers exist when the surface temperature and the nanoparticle species diffusion differs from that of fluid temperature as well as nanoparticles species diffusion. Using the following similarity transformation (see Das et al. (2016))

$$
\begin{aligned}
\eta & =\frac{z}{H \sqrt{1-\alpha t}}, u=\frac{\alpha r}{2(1-\alpha t)} f^{\prime}(\eta), w \\
& =-\frac{\alpha H}{\sqrt{1-\alpha t}} f(\eta), \theta=\frac{T-T_{h}}{T_{w}-T_{h}}, \quad \phi=\frac{C-C_{h}}{C_{w}-C_{h}}
\end{aligned}
$$

Equations (2) and (3) reduce to

$$
\left(f^{\prime \prime}\left(1-\frac{\theta}{\theta_{r}}\right)^{-1}\right)^{\prime \prime}-S\left(\eta f^{\prime \prime \prime}+3 f^{\prime \prime}-2 f f^{\prime \prime \prime}\right)-M n f^{\prime \prime}=0 .
$$

Now, Eqs. (4) and (5) take the following forms with the associated boundary conditions

$$
\begin{array}{r}
\left.\begin{array}{rl}
\left(\left(1+\varepsilon_{1} \theta\right) \theta^{\prime}\right)^{\prime} & +\operatorname{Pr} S\left(2 f \theta^{\prime}-\eta \theta^{\prime}\right) \\
& +\operatorname{Pr} \theta^{\prime}\left(N b \phi^{\prime}\left(1+\varepsilon_{2} \phi\right)+N t \theta^{\prime}\right)=0, \\
\left(\left(1+\varepsilon_{2} \phi\right) \phi^{\prime}\right)^{\prime}+\operatorname{Le} S\left(2 f \phi^{\prime}-\eta \phi^{\prime}\right)+\frac{N t}{N b} \theta^{\prime \prime}=0, & (12) \\
f(\eta)=A, f^{\prime}(\eta)+\beta f^{\prime \prime}(\eta)=0, \theta(\eta)+\gamma \theta^{\prime}(\eta)=1, \phi(\eta)=1 \text { at } \eta=0 \\
f(\eta)=\frac{1}{2}, f^{\prime}(\eta)-\beta f^{\prime \prime}(\eta)=0, \theta(\eta)-\gamma \theta^{\prime}(\eta)=0, \phi(\eta)=0 \text { at } \eta=1
\end{array}\right\} .
\end{array}
$$

The non-dimensional parameters $\theta_{n} S, M n, \operatorname{Pr}, N b, N t, L e$, $A, \varepsilon_{1}, \varepsilon_{2}, \beta$, and $\gamma$ denote respectively the fluid viscosity parameter, squeeze parameter, magnetic parameter, Prandtl number, Brownian motion parameter, thermophoresis parameter, the Lewis number, the suction/injection parameter, the variable thermal conductivity parameter, the variable species diffusivity parameter, the velocity slip parameter, and the temperature slip parameter. They are defined as

$$
\begin{aligned}
& S=\frac{\alpha H^{2}}{2 v_{\infty}}, M n=\frac{H^{2} \sigma B_{0}^{2}}{v_{\infty}}, \operatorname{Pr}=\frac{\nu_{\infty}}{\lambda}, N b=\frac{\tau D_{B}\left(C_{w}-C_{h}\right)}{v_{\infty}}, \\
& N t=\frac{\tau D_{T}\left(T_{w}-T_{h}\right)}{\nu_{\infty} T_{m}}, L e=\frac{\nu_{\infty}}{D_{B}}, A=\frac{w_{0}}{\alpha H}, \beta=\frac{\beta_{1}}{H \sqrt{1-\alpha t}}, \\
& \gamma=\frac{\gamma_{1}}{H \sqrt{1-\alpha t}} .
\end{aligned}
$$

Physically, squeeze parameter $S>0$ corresponds to plates moving apart and $S<0$ to the plates moving closer. Furthermore, transpiration (suction/injection) $A>0$ corresponds to suction and $A<0$ to injection at the lower stationary disk. In the absence of variable fluid properties (i. e., $\theta_{r}=\varepsilon_{1}=\varepsilon_{2}=0$ ), slip velocity (i. e., $\beta=0$ ), and slip temperature (i. e., $\gamma=0$ ), Eqs. (10) to (13) reduce to those of Hashmi et al. (2012). Also, in the absence of variable fluid properties (i. e., $\theta_{r}=\varepsilon_{1}=\varepsilon_{2}=0$ ) the set of equations with boundary conditions (14) reduces to those of Das et al. (2016). The quantities of physical interest are the skin friction coefficient $C_{\mathrm{fr}}$ the Nusselt number $N_{\mathrm{ur}}$ and the Sherwood number $S_{\mathrm{hr}}$ which are defined as follows:

$$
\begin{aligned}
C_{\mathrm{fr}} & =\frac{\left.\mu_{\infty}\left(\frac{\partial u}{\partial z}+\frac{\partial w}{\partial r}\right)\right|_{z=h(t)}}{\rho_{\infty}\left(\frac{-\alpha H}{2 \sqrt{1-\alpha t}}\right)^{2}}, N_{\mathrm{ur}}=\frac{-\left.H\left(\frac{\partial T}{\partial z}\right)\right|_{z=h(t)}}{\left(T_{w}-T_{h}\right)}, \\
S_{\mathrm{hr}} & =\frac{-\left.H\left(\frac{\partial C}{\partial z}\right)\right|_{z=h(t)}}{\left(C_{w}-C_{h}\right)} .
\end{aligned}
$$

In terms of (9), these expressions reduce to

$$
\begin{aligned}
C_{\mathrm{fr}} & =\frac{H^{2}}{r^{2}} C_{f} \operatorname{Re}_{r}=f^{\prime \prime}(1), N_{\mathrm{ur}}=\sqrt{(1-\alpha t)} N u \\
& =-\theta^{\prime}(1), S_{\mathrm{hr}}=\sqrt{(1-\alpha t)} S h=-\phi^{\prime}(1)
\end{aligned}
$$

where $\operatorname{Re}_{r}=\frac{r \alpha H \sqrt{(1-\alpha t)}}{2 v_{\infty}}$ is the local squeeze Reynolds number.

\section{Methods}

Semi-analytical solution: optimal homotopy analysis method (OHAM)

The governing equations are highly non-linear, coupled ODEs with variable coefficients. We use optimal homotopy analysis method (OHAM) to obtain appropriate analytic solutions for Eqs. (10)-(12) with associated boundary conditions (13). The OHAM is based on the homotopy concept from topology. In this regard, a nonlinear problem is transformed into an infinite number of linear sub-problems. In the framework of OHAM, we have great freedom to choose the auxiliary linear operators and initial approximations. This is advantageous over other iterative techniques, where convergence is largely tied to a good initial approximation of the solution. The OHAM differs from other analytic approximation methods as it does not depend on small or large physical parameters. This is achieved by inclusion of an artificial "convergence control parameter," which guarantees convergence of the solution series. The OHAM has been successfully applied to a wide variety of non-linear problems (for details see Liao (2003) Fan and You (2013)). Optimal homotopy analysis method is employed to solve the system of non-linear Eqs. (10)-(12) with boundary conditions (13). 
In the outline of the OHAM, the non-linear equations are decomposed into their linear parts as follows. In accordance with the boundary conditions (13), the base functions are chosen as $\left\{a_{m} \eta^{m} / m \geq 0\right\}$, then the dimensionless velocity $f(\eta)$, temperature $\theta(\eta)$, and concentration $\phi(\eta)$ can be expressed in the series form as follows

$$
\begin{aligned}
f(\eta) & =\sum_{k=0}^{\infty} a_{k} \eta^{k}, \theta(\eta)=\sum_{k=0}^{\infty} b_{k} \eta^{k} \text { and } \phi(\eta) \\
& =\sum_{n=1}^{\infty} c_{k} \eta^{k}
\end{aligned}
$$

where $a_{k}, b_{k}$, and $c_{k}$ are the coefficients. According to the rule of solution expression and boundary conditions (13), we assume the following:

Initial guesses for dimensionless velocity $f(\eta)$, temperature $\theta(\eta)$, and concentration $\phi(\eta)$ as

$$
\left.\begin{array}{rl}
f_{0}(\eta)= & A-\eta \frac{(3-6 A)(\beta-1 / 2) \beta}{2 \beta(2-3 \beta)-1 / 2}+\eta^{2} \frac{(3-6 A)(\beta-1 / 2)}{2(2 \beta(2-3 \beta)-1 / 2)} \\
& +\frac{\eta^{3}}{6}\left[(3-6 A)-\frac{3(3-6 A(\beta-1 / 2))}{2 \beta(2-3 \beta)-1 / 2}+\frac{6(3-6 A)(\beta-1 / 2) \beta}{2 \beta(2-3 \beta)-1 / 2}\right], \\
\theta_{0}(\eta)= & \frac{1-\gamma}{1-2 \gamma}-\frac{\eta}{1-2 \gamma} \text { and } \phi_{0}(\eta)=1-\eta
\end{array}\right\} .
$$

Linear operators $L_{f} L_{\theta}$, and $L_{\phi}$ as

$$
\begin{aligned}
& L_{f}=\frac{d^{4}}{d \eta^{4}}, L_{\theta}=\frac{d^{2}}{d \eta^{2}} \text {, and } L_{\phi}=\frac{d^{2}}{d \eta^{2}} \quad \text { such that } \\
& L_{f}\left[c_{1}+c_{2} \eta+c_{3} \frac{\eta^{2}}{2}+c_{4} \frac{\eta^{3}}{6}\right]=0, L_{\theta}\left[c_{5}+c_{6} \eta\right] \\
& \quad=0 \text { and } L_{\phi}\left[c_{7}+c_{8} \eta\right]=0
\end{aligned}
$$

where $c_{i}{ }^{\prime} s(i=1,2,3,4,5,6,7,8)$ are arbitrary constants and $H_{f}(\eta)=H_{\theta}(\eta)=H_{\phi}(\eta)=1$ are auxiliary functions.

Let us consider so called zeroth order deformation approximations as

$$
(1-q) L_{f}\left[\hat{f}(\eta, q)-f_{0}(\eta)\right]=q H_{f}(\eta) \widehat{h}_{f} N_{f}[\hat{f}(\eta, q), \hat{\theta}(\eta, q)]
$$

$(1-q) L_{\theta}\left[\hat{\theta}(\eta, q)-\theta_{0}(\eta)\right]=q H_{\theta}(\eta) \widehat{h}_{\theta} N_{\theta}[\hat{\theta}(\eta, q), \hat{f}(\eta, q), \hat{\phi}(\eta, q)]$,

$(1-q) L_{\phi}\left[\hat{\phi}(\eta, q)-\hat{\phi}_{0}(\eta)\right]=q H_{\phi}(\eta) \widehat{h}_{\phi} N_{\phi}[\hat{\phi}(\eta, q), \hat{f}(\eta, q), \hat{\theta}(\eta, q)]$

with conditions

$$
\begin{aligned}
& \hat{f}(0, q)=A, \hat{f}^{\prime}(0, q)+\beta \hat{f^{\prime \prime}}(0, q)=0, \hat{f}(1, q)=\frac{1}{2}, \hat{f}(1, q)-\beta \hat{f}^{\prime \prime}(1, q)=0 ; \\
& \hat{\theta}(0, q)+\gamma \hat{\theta}(0, \eta)=1, \hat{\theta}(1, q)-\gamma \hat{\theta}(1, \eta)=0 ; \quad \hat{\phi}(0, q)=1, \hat{\phi}(1, q)=0 .
\end{aligned}
$$

where $q \in[0,1]$ is an embedding parameter and $\left(\widehat{h}_{f}, \widehat{h}_{\theta}, \widehat{h}_{\phi}\right) \neq 0$ are the convergence control parameters. Here, $N_{f} N_{\theta}$, and $N_{\phi}$ are non-linear operators defined as

$$
\begin{aligned}
N_{f}= & \left(1-\frac{\hat{\theta}(\eta, q)}{\theta_{r}}\right)^{2} \hat{f}^{i v}(\eta, q)+\left(1-\frac{\hat{\theta}(\eta, q)}{\theta_{r}}\right) \frac{2 f^{\prime \prime \prime}(\eta, q) \hat{\theta^{\prime}}(\eta, q)}{\theta_{r}} \\
& +\left(1-\frac{\hat{\theta}(\eta, q)}{\theta_{r}}\right) \frac{\hat{f}^{\prime \prime}(\eta, q) \hat{\theta}^{\prime \prime}(\eta, q)}{\theta_{r}}+\frac{2 \hat{f}^{\prime \prime}(\eta, q) \hat{\theta}^{2}(\eta, q)}{\theta_{r}{ }^{2}} \\
& -\left(1-\frac{\hat{\theta}(\eta, q)}{\theta_{r}}\right)^{3} S\left(\eta f^{\prime \prime \prime}(\eta, q)+3 \hat{f}^{\prime \prime}(\eta, q)-2 \hat{f}(\eta, q) \hat{f}^{\prime \prime \prime}(\eta, q)\right) \\
& -M n^{2}\left(1-\frac{\hat{\theta}(\eta, q)}{\theta_{r}}\right)^{3} \hat{f}^{\prime \prime}(\eta, q), \\
N_{\theta}= & \left(\left(1+\varepsilon_{1} \hat{\theta}(\eta, q)\right) \hat{\theta^{\prime}}(\eta, q)\right)+\operatorname{Pr} S\left(2 \hat{f}(\eta, q) \hat{\theta}(\eta, q)-\eta \hat{\theta^{\prime}}(\eta, q)\right) \\
& +\operatorname{Pr} N b \hat{\theta^{\prime}}(\eta, q) \hat{\phi}^{\prime}(\eta, q)+\operatorname{Pr} N b \varepsilon_{2} \hat{\phi}(\eta, q) \hat{\theta^{\prime}}(\eta, q) \hat{\phi}^{\prime}(\eta, q) \\
& +\operatorname{Pr} N t \hat{\theta}^{2}(\eta, q), \\
N_{\phi}= & \left(\left(1+\varepsilon_{2} \hat{\phi}(\eta, q)\right) \hat{\phi}(\eta, q)\right) \\
& +L e S(2 \hat{f}(\eta, q) \hat{\phi}(\eta, q)-\eta \hat{\phi}(\eta, q)) \\
& +\frac{N t}{N b} \hat{\theta^{\prime \prime}}(\eta, q) .
\end{aligned}
$$

From Eqs. (18) to (20), at $q=0$, we have

$$
\begin{aligned}
L_{f}\left[\hat{f}(\eta, 0)-f_{0}(\eta)\right] & =0, L_{\theta}\left[\hat{\theta}(\eta, 0)-\theta_{0}(\eta)\right] \\
& =0, \text { and } L_{\phi}\left[\hat{\phi}(\eta, 0)-\hat{\phi}_{0}(\eta)\right]=0
\end{aligned}
$$

which implies that $\hat{f}(\eta, 0)=f_{0}(\eta), \hat{\theta}(\eta, 0)=\theta_{0}(\eta)$, and $\hat{\phi}(\eta, 0)=\hat{\phi}_{0}(\eta)$ respectively, whereas at $q=1$, we have

$$
N_{f}[\hat{f}(\eta, 1), \hat{\theta}(\eta, 1)]=0, N_{\theta}[\hat{\theta}(\eta, 1), \hat{f}(\eta, 1), \hat{\phi}(\eta, 1)]=
$$

0 , and $N_{\phi}[\hat{\phi}(\eta, 1), \hat{f}(\eta, 1), \hat{\theta}(\eta, 1)]=0 \quad$ which implies that $\hat{f}(\eta, 1)=f(\eta), \hat{\theta}(\eta, 1)=\theta(\eta)$, and $\hat{\phi}(\eta, 1)=\phi(\eta)$ respectively.

Hence, by defining

$$
\begin{aligned}
& f_{m}(\eta)=\left.\frac{1}{m !} \frac{d^{m} f(\eta, q)}{d \eta^{m}}\right|_{q=0}, \theta_{m}(\eta)=\left.\frac{1}{m !} \frac{d^{m} \theta(\eta, q)}{d \eta^{m}}\right|_{q=0}, \\
& \phi_{m}(\eta)=\left.\frac{1}{m !} \frac{d^{m} \phi(\eta, q)}{d \eta^{m}}\right|_{q=0}
\end{aligned}
$$

we expand $\hat{f}(\eta, q), \hat{\theta}(\eta, q)$, and $\hat{\phi}(\eta, q)$ by means of Taylor's series as

$$
\begin{aligned}
\hat{f}(\eta, q)= & f_{0}(\eta)+\sum_{m=1}^{\infty} f_{m}(\eta) q^{m}, \\
\hat{\theta}(\eta, q)= & \theta_{0}(\eta)+\sum_{m=1}^{\infty} \theta_{m}(\eta) q^{m}, \text { and } \hat{\phi}(\eta, q)=\phi_{0}(\eta) \\
& +\sum_{m=1}^{\infty} \phi_{m}(\eta) q^{m} .
\end{aligned}
$$


If series (21) converges at $q=1$, we get the homotopy series solutions

$$
\begin{aligned}
& f(\eta)=f_{0}(\eta)+\sum_{m=1}^{\infty} f_{m}(\eta), \quad \theta(\eta)=\theta_{0}(\eta)+\sum_{m=1}^{\infty} \theta_{m}(\eta), \quad \text { and } \\
& \phi(\eta)=\phi_{0}(\eta)+\sum_{m=1}^{\infty} \phi_{m}(\eta) .
\end{aligned}
$$

\section{Optimal convergence control parameter}

It should be noted that $f(\eta), \theta(\eta)$, and $\phi(\eta)$ in Eq. (22) contain the unknown convergence control parameters $\widehat{h}_{f}, \widehat{h}_{\theta}$, and $\widehat{h}_{\phi}$ which can be used to adjust and control the convergence region and the rate of convergence of the homotopy series solution. The $m$ th order deformation equations and the conditions are as follows:

$$
\begin{aligned}
& L_{f}\left[f_{m}(\eta)-\chi_{m} f_{m-1}(\eta)\right]=H_{f}(\eta) \widehat{h}_{f} R_{m}{ }^{f}(\eta), \\
& L_{\theta}\left[\theta_{m}(\eta)-\chi_{m} \theta_{m-1}(\eta)\right]=H_{\theta}(\eta) \widehat{h}_{\theta} R_{m}{ }^{\theta}(\eta), \\
& L_{\phi}\left[\phi_{m}(\eta)-\chi_{m} \phi_{m-1}(\eta)\right]=H_{\phi}(\eta) \widehat{h}_{\phi} R_{m}{ }^{\phi}(\eta),
\end{aligned}
$$

with $f_{m}(0)=0, f_{m}^{\prime}(0)+\beta f_{m}^{\prime \prime}(0)=0, f_{m}(1)=0, f_{m}^{\prime}(1)$ $-\beta f_{m}^{\prime \prime}(1)=0,{ }^{\prime} \theta_{m}(0)+\gamma \theta^{\prime}(0)=0, \theta_{m}(1)-\gamma \theta^{\prime}(1)=0$, $\phi_{m}(0)=0, \phi_{m}(1)=0$, where

$$
\begin{aligned}
R_{m}{ }^{\theta}=\theta_{m-1}^{\prime \prime} & +\varepsilon_{1}\left(\sum_{k=0}^{m-1} \theta_{m-1-k}^{\prime \prime} \theta_{k}+\sum_{k=0}^{m-1} \theta_{m-1-k}^{\prime} \theta_{k}^{\prime}\right) \\
& +\operatorname{Pr} S\left(2 \sum_{k=0}^{m-1} \theta_{m-1-k}^{\prime} f_{k}-\eta \theta_{m-1}^{\prime}\right) \\
& +\operatorname{Pr} N b \sum_{k=0}^{m-1} \theta_{m-1-k}^{\prime} \phi_{k}^{\prime}+\operatorname{Pr} N b \varepsilon_{2} \sum_{k=0}^{m-1} \phi_{m-1-k}^{\prime} \sum_{j=0}^{k} \theta_{k-j}^{\prime} \phi_{j} \\
& +\operatorname{Pr} N t \sum_{k=0}^{m-1} \theta_{m-1-k}^{\prime} \theta_{k}^{\prime} \\
R_{m}{ }^{\phi}= & \phi_{m-1}^{\prime \prime}(\eta)+\varepsilon_{2}\left(\sum_{k=0}^{m-1} \phi_{m-1-k}^{\prime \prime} \phi_{k}+\sum_{k=0}^{m-1} \phi_{m-1-k}^{\prime} \phi_{k}^{\prime}\right) \\
+ & \operatorname{LeS}\left(2 \sum_{k=0}^{m-1} \phi_{m-1-k}^{\prime} f_{k}-\eta \phi_{m-1}^{\prime}\right)+\frac{N t}{N b} \theta_{m-1}^{\prime \prime}
\end{aligned}
$$

and

$$
X_{m}=\left\{\begin{array}{c}
0, m \leq 1 \\
1, m>1
\end{array}\right.
$$

\section{Error analysis}

Now we evaluate the error and minimize over $\widehat{h}_{f}, \widehat{h}_{\theta}$, and $\widehat{h}_{\phi}$ in order to obtain the optimal values for $\widehat{h}_{f}, \widehat{h}_{\theta}$, and $\widehat{h}_{\phi}$ and the least possible error. In the process of error analysis, two different methods are employed, namely, exact residual error and average residual error. For different order approximation, CPU time required

$$
\begin{aligned}
R_{m}{ }^{f}=f^{i v}{ }_{m-1} & +\left(\frac{1}{\theta_{r}^{2}}\right) \sum_{k=0}^{m-1} f^{i v}{ }_{m-1-k} \sum_{j=0}^{k} \theta_{k-j} \theta_{j}-\left(\frac{2}{\theta_{r}}\right) \sum_{k=0}^{m-1} f^{i v}{ }_{m-1-k} \theta_{k}+\left(\frac{2}{\theta_{r}}\right) \sum_{k=0}^{m-1} f_{m-1-k}^{\prime \prime} \theta_{k}^{\prime}-\left(\frac{2}{\theta_{r}^{2}}\right) \sum_{k=0}^{m-1} f_{m-1-k}^{\prime \prime \prime} \sum_{j=0}^{k} \theta_{k-j^{\prime}} \theta_{j} \\
& +\left(\frac{1}{\theta_{r}}\right) \sum_{k=0}^{m-1} f_{m-1-k}^{\prime \prime} \theta_{k}^{\prime \prime}-\left(\frac{1}{\theta_{r}^{2}}\right) \sum_{k=0}^{m-1} f_{m-1-k}^{\prime \prime} \sum_{j=0}^{k} \theta_{k-j}^{\prime \prime} \theta_{j}+\left(\frac{2}{\theta_{r}^{2}}\right) \sum_{k=0}^{m-1} f_{m-1-k}^{\prime \prime} \sum_{j=0}^{k} \theta_{k-j}^{\prime} \theta_{j}^{\prime}-S \eta f_{m-1}^{\prime \prime \prime} \\
& +\left(\frac{S \eta}{\theta_{r}^{3}}\right) \sum_{k=0}^{m-1} f_{m-1-k}^{\prime \prime \prime} \sum_{j=0}^{k} \theta_{k-j} \sum_{i=0}^{j} \theta_{j-i} \theta_{i}+\left(\frac{3 S \eta}{\theta_{r}}\right) \sum_{k=0}^{m-1} f_{m-1-k}^{\prime \prime \prime} \theta_{k}-\left(\frac{3 S \eta}{\theta_{r}^{2}}\right) \sum_{k=0}^{m-1} f_{m-1-k}^{\prime \prime \prime} \sum_{j=0}^{k} \theta_{k-j} \theta_{j}-3 S f_{m-1}^{\prime \prime} \\
& +\left(\frac{3 S}{\theta_{r}^{3}}\right) \sum_{k=0}^{m-1} f_{m-1-k}^{\prime \prime} \sum_{j=0}^{k} \theta_{k-j} \sum_{i=0}^{j} \theta_{j-i} \theta_{i}+\left(\frac{9 S}{\theta_{r}}\right) \sum_{k=0}^{m-1} f_{m-1-k}^{\prime \prime} \theta_{k}-\left(\frac{9 S}{\theta_{r}^{2}}\right) \sum_{k=0}^{m-1} f_{m-1-k}^{\prime \prime} \sum_{j=0}^{k} \theta_{k-j} \theta_{j}+2 S \sum_{k=0}^{m-1} f_{m-1-k}^{\prime \prime \prime} f_{k} \\
& -\left(\frac{2 S}{\theta_{r}^{3}}\right) \sum_{k=0}^{m-1} f_{m-1-k}^{\prime \prime \prime} \sum_{j=0}^{k} f_{k-j} \sum_{i=0}^{j} \theta_{j-i} \sum_{l=0}^{i} \theta_{i-l} \theta_{l}-\left(\frac{6 S}{\theta_{r}}\right) \sum_{k=0}^{m-1} f_{m-1-k}^{\prime \prime \prime} \sum_{j=0}^{k} f_{k-j} \theta_{j} \\
& +\left(\frac{6 S}{\theta_{r}^{2}}\right) \sum_{k=0}^{m-1} f_{m-1-k}^{\prime \prime \prime} \sum_{j=0}^{k} f_{k-j} \sum_{i=0}^{j} \theta_{j-i} \theta_{i}-M^{2} f_{m-1}^{\prime \prime}+\left(\frac{M^{2}}{\theta_{r}^{3}}\right) \sum_{k=0}^{m-1} f_{m-1-k}^{\prime \prime} \sum_{j=0}^{k} \theta_{k-j} \sum_{i=0}^{j} \theta_{j-i} \theta_{i} \\
& +\left(\frac{3 M^{2}}{\theta_{r}}\right) \sum_{k=0}^{m-1} f_{m-1-k}^{\prime \prime} \theta_{k}-\left(\frac{3 M^{2}}{\theta_{r}^{2}}\right) \sum_{k=0}^{m-1} f_{m-1-k}^{\prime \prime} \sum_{j=0}^{k} \theta_{k-j} \theta_{j}
\end{aligned}
$$


for evaluation of $f^{\prime \prime}(1)$ is observed. As for the CPU time is concerned, the average residual error needs less time compared to that of the exact residual error for increasing values of $m$ (for details, see Table 1). At the $m$ th order deformation equation, the exact residual errors are given by

$$
\begin{aligned}
\hat{E}_{m}{ }^{f} & =\int_{0}^{1}\left(N_{1}\left[\sum_{n=0}^{m} f_{n}(\eta)\right]\right)^{2} d \eta \\
\hat{E}_{m}{ }^{\theta} & =\int_{0}^{1}\left(N_{2}\left[\sum_{n=0}^{m} \theta_{n}(\eta)\right]\right)^{2} d \eta \\
\hat{E}_{m}{ }^{\phi} & =\int_{0}^{1}\left(N_{3}\left[\sum_{n=0}^{m} \phi_{n}(\eta)\right]\right)^{2} d \eta .
\end{aligned}
$$

But in practice the evaluation of $\hat{E}_{m}^{f}, \hat{E}_{m}^{\theta}$, and $\hat{E}_{m}^{\phi}$ is much time-consuming so instead of exact residual errors, we use average residual errors defined as

$$
\begin{aligned}
& E_{m}{ }^{f}=\frac{1}{M+1} \sum_{k=0}^{M}\left(N_{f}\left[\sum_{n=0}^{m} f_{n}\left(\eta_{k}\right)\right]\right)^{2}, \\
& E_{m}{ }^{\theta}=\frac{1}{M+1} \sum_{k=0}^{M}\left(N_{\theta}\left[\sum_{n=0}^{m} \theta_{n}\left(\eta_{k}\right)\right]\right)^{2} \text {, } \\
& E_{m}{ }^{\phi}=\frac{1}{M+1} \sum_{k=0}^{M}\left(N_{\phi}\left[\sum_{n=0}^{m} \phi_{n}\left(\eta_{k}\right)\right]\right)^{2} \text {, and } \\
& E_{m}^{t}=E_{m}{ }^{f}+E_{m}{ }^{\theta}+E_{m}{ }^{\phi}
\end{aligned}
$$

where $E_{m}^{t}$ is the total squared residual error, $\eta_{k}=k \Delta \eta=\frac{k}{M}$, $k=0,1,2, \ldots . M$. Now the error functions $E_{m}^{f}, E_{m}^{\theta}$, and $E_{m}^{\phi}$ are minimized over $\widehat{h}_{f}, \widehat{h}_{\theta}$, and $\widehat{h}_{\phi}$ to obtain the optimal values. Evidently, $\lim _{m \rightarrow \infty} E_{m}{ }^{f}=0, \lim _{m \rightarrow \infty} E_{m}{ }^{\theta}=0, \lim _{m \rightarrow \infty}$ $E_{m}{ }^{\phi}=0$ correspond to a convergent series solution. Average residual errors for $f, \theta$, and $\phi$ are obtained by considering the optimal values of $\widehat{h}_{f}(-0.821699), \widehat{h}_{\theta}$ $(-0.919399)$, and $\widehat{h}_{\phi}(-0.918880)$ in Table 3, which has been obtained by minimizing the squared residual

\begin{tabular}{|c|c|c|c|c|}
\hline \multirow{2}{*}{$\begin{array}{l}\text { Order } \\
m\end{array}$} & \multicolumn{2}{|c|}{ Using exact residual error } & \multicolumn{2}{|c|}{ Using average residual error } \\
\hline & $-f^{\prime \prime}(1)$ & CPU time $(\mathrm{s})$ & $-f^{\prime \prime}(1)$ & CPU time (s) \\
\hline 1 & 2.87099 & 9.83 & 2.87063 & 0.61 \\
\hline 2 & 2.86492 & 26.86 & 2.86492 & 2.14 \\
\hline 3 & 2.84464 & 73.93 & 2.84498 & 5.94 \\
\hline 4 & 2.84315 & 1234.25 & 2.84332 & 14.43 \\
\hline
\end{tabular}
errors of $f, \theta$, and $\phi$ at the approximation $m=6$ as shown in Table 2. It is observed from Table 3 that

Table 1 Comparison of $f^{\prime \prime}(1)$ and CPU time (s) incurred to evaluate the $m$ th order approximation by exact residual error and average residual error when $M=\operatorname{Pr}=1, S=N b=N t=0.5$, $L e=2, A=0.01, \gamma=\varepsilon_{1}=\varepsilon_{2}=0.1, \theta_{r}=-5.0$, and $\beta=0.01$.
CPU time increases consistently as the approximation increases and with the increase of order of approximation, the average residual error for $f, \theta$, and $\phi$ decreases continuously. Hence, the optimal value of $f, \theta$, and $\phi$ helps in the fastest convergence of solution series. Substituting these optimal values of $\widehat{h}_{f}, \widehat{h}_{\theta}$, and $\widehat{h}_{\phi}$ in Eq. (22), we get the approximate solutions of Eqs. (10) to (12) satisfying the boundary conditions (13).

\section{Results and discussion}

The system of Eqs. (10) to (12) is highly non-linear coupled ordinary differential equations. The system of equations with the boundary conditions (13) is solved analytically via efficient OHAM. In order to validate the method and to judge the accuracy of the analysis, the values of the skin friction, local Nusselt number, and the local Sherwood number are compared with the previously published results for special cases in which the thermo-physical fluid properties are neglected (see Tables 4, 5, and 6). It can be found from Tables 4, 5, and 6 that the present results agree very well with those of Hashmi et al. (2012) and Das et al. (2016).

On employing the above analytical schemes, the system of equations are solved for several sets of values of the pertinent parameters, namely, the fluid viscosity parameter $\theta_{n}$ the squeeze parameter $S$, the magnetic parameter $M n$, the Prandtl number $\mathrm{Pr}$, the thermophoresis parameter $N t$, the Brownian motion parameter $N b$, the variable thermal conductivity parameter $\varepsilon_{1}$, the variable species diffusivity parameter $\varepsilon_{2}$, the Lewis number $L e$, the suction/injection parameter $A$, velocity slip parameter $\beta$, and the temperature slip parameter $\gamma$. In order to get clear insight into the effects of these parameters on flow characteristics, the obtained results are analyzed graphically in Figs. 2, 3, and 5. It may be note that, $\theta_{r}<0$ for liquids and $\theta_{r}>0$ for gasses. This is due to the fact that viscosity of a liquid decreases with increasing temperature while it increases for gasses. Hence, in this steady, we considered negative values of $\theta_{r}$. The computed numerical values for $f^{\prime \prime}(1), \theta^{\prime}(1)$, and $\phi^{\prime}(1)$ are tabulated in Table 7.

\section{Velocity field}

The effect of $\theta_{n} M n, S$, and $\beta$ on the velocity distribution $f^{\prime}(\eta)$ for transpiration (suction/blowing) is elucidated in Fig. 2a-d. Here, the profiles are parabolic in nature. In general, at the central region, these profiles exhibit the cross-flow behavior and also exhibit the dual behavior with the increase in the pertinent parameters. From Fig. 2a it is clear that, for higher values of $\theta_{n}$ the velocity profile increases near the walls where the transpiration effects are dominant when $\eta \leq 0.44, \eta \leq 0.46$, and $\eta \leq 0.49$. However, for $\eta>0.44, \eta>0.46$, and $\eta>0.49$, 
Table 2 Values of convergence control parameters $h_{f}, h_{\theta}$, and $h_{\varphi}$ and the corresponding total residual errors $E_{m}^{t}$ for different orders of approximation $m$ with $S=M=0.1, \operatorname{Pr}=0.72, \gamma=0.1, \mathrm{Nb}=\mathrm{Nt}=0.1, \mathrm{Le}=1, A=0.01, \varepsilon_{1}=\varepsilon_{2}=0.1, \theta_{r}=-10.0, \beta=0.1$.

\begin{tabular}{lllllr}
\hline$m$ & $-h_{f}$ & $-h_{\theta}$ & $-h_{\phi}$ & $E_{m}^{t}$ & \\
\hline 1 & 0.855974 & 0.913900 & 0.213443 & $2.51 \times 10^{-1}$ & 1.14 \\
2 & 0.914521 & 0.894988 & 0.120164 & $1.08 \times 10^{-2}$ & \\
3 & 0.905082 & 0.873693 & 0.917802 & $2.98 \times 10^{-4}$ & 14.92 \\
4 & 0.886267 & 0.835341 & 0.896250 & $5.54 \times 10^{-6}$ & 38.95 \\
5 & 0.858155 & 0.913425 & 0.876598 & $2.40 \times 10^{-7}$ & 72.10 \\
6 & 0.821699 & 0.919399 & 0.918880 & $3.42 \times 10^{-8}$ & 74.52 \\
\hline
\end{tabular}

the velocity profiles decreases as $\theta_{r} \rightarrow 0$. This may be attributed to the fact that, for a given base fluid (air or water), when $\zeta$ is fixed, lesser $\theta_{r}$ implies higher temperature difference between the wall and the ambient fluid. Hence, the results explicitly manifest that $\theta_{r}$ is the indicator of the variation of fluid viscosity with temperature which has a substantial effect on $f^{\prime}(\eta)$ and hence on $f^{\prime \prime}(1)$ (see Table 7 for details). The effect of $M n$ on $f^{\prime}(\eta)$ is demonstrated in Fig. 2b. It is observed that, for the higher values of $M n$, the fluid velocity increase and thereby decrease the thickness of the momentum boundary layer near the wall region, for absence of suction/injection parameter and $0.23 \geq \eta \geq 0.67$ for suction) However, the reverse trend is observed in the central region. This dual behavior of the flow is due to the mass conservation constraint (see Lawal and Kalyon (1998)). Figure 2c depicts the behavior of $S$ on $f^{\prime}(\eta)$ It is seen that $f^{\prime}(\eta)$ decreases with an increase in $S$ at the central region for suction $(0.32 \leq \eta \leq 0.74)$ and the reverse trend is recorded in the case of injection. Physically, in the case of suction, there will be an increase in $h(t)$ which will cause it to decrease in velocity and the increase in squeezing parameter. Further, when $\eta \leq 0.32$ or $\eta \leq 0.74$, that is the neighborhood of 0.32 and 0.74 , there will be a corresponding decrease in $h(t)$ which in turn will increase in both fluid velocity and squeezing parameter. The effect of $\beta$ on $f^{\prime}(\eta)$ is shown in Fig. 2d. The behavior of $f^{\prime}(\eta)$ at the surface of the disks is zero when $\beta=0$ (no slip at the wall). For the suction flow, an increase in $\beta$ strengthens the $f^{\prime}(\eta)$ near the wall, that is for $\eta \geq 0.16$ and $\eta \geq 0.82$, while at the central region, rising $\beta$ results in weakening of $f^{\prime}(\eta)$. However, for the case of injection, the effect of $f$ ' $(\eta)$ is opposite to that accounted for suction flow. Physically, in the case of injection, an increase in $f^{\prime}(\eta)$ near the wall region with increasing $\beta$ gives rise to a decrease in velocity gradient at there. However, when the mass flow rate is kept constant, an increase in the fluid velocity near the wall region will be remunerated by an analogous fall in the fluid velocity near the mid region so that mass conservation limitation will not be dishonored (see ref. (Lawal and Kalyon 1998)).

\section{Temperature distribution and nanoparticle volume distribution}

The effects of $S, \gamma, \varepsilon_{1}, \mathrm{Pr}$, and $N t$ on the temperature distribution $\theta(\eta)$ for transpiration are presented in Fig. 3a-c. Figure 3a illustrates the effect of $S$ on $\theta(\eta)$. For larger $S$, the temperature distribution reduces in the case of suction whereas the reverse trend is observed in the case of injection. Higher values of $S$ indicate a decrease in the kinematic viscosity which depends on the velocity and distance between disks. The effect of $\gamma$ on $\theta(\eta)$ is depicted in Fig. 3b. It is observed that in the absence of thermal slip (when $\gamma=0$ ); the temperature of the fluid and temperature of the disks' surfaces remain same (here, 0 for the lower disk and 1 for the upper disk). These results are found to

Table 3 Individual average residual error with $S=M=0.1, \operatorname{Pr}=0.72, \gamma=0.1, \mathrm{Nb}=\mathrm{Nt}=0.1, \mathrm{Le}=1, A=0.01, \varepsilon_{1}=\varepsilon_{2}=0.1, \theta_{r}=-10.0, \beta=0.1$.

\begin{tabular}{llllr}
\hline$m$ & $E_{m}^{f}$ & $E_{m}^{\theta}$ & $E_{m}^{\phi}$ & $C \mathrm{CPU}$ time (s) \\
\hline 1 & $1.85 \times 10^{-1}$ & $4.24 \times 10^{-3}$ & $1.09 \times 10^{-1}$ & 0.17 \\
2 & $1.02 \times 10^{-2}$ & $1.15 \times 10^{-4}$ & $7.63 \times 10^{-3}$ & 1.33 \\
3 & $5.44 \times 10^{-4}$ & $4.05 \times 10^{-6}$ & $2.06 \times 10^{-4}$ & 4.84 \\
4 & $1.94 \times 10^{-5}$ & $1.82 \times 10^{-7}$ & $8.31 \times 10^{-6}$ & 13.63 \\
5 & $3.64 \times 10^{-7}$ & $7.83 \times 10^{-9}$ & $4.67 \times 10^{-7}$ & 33.22 \\
6 & $4.13 \times 10^{-9}$ & $2.58 \times 10^{-10}$ & $2.68 \times 10^{-8}$ & 71.22 \\
7 & $2.55 \times 10^{-9}$ & $7.23 \times 10^{-12}$ & $1.01 \times 10^{-9}$ & 139.98 \\
8 & $5.32 \times 10^{-10}$ & $1.62 \times 10^{-13}$ & $3.31 \times 10^{-11}$ & 280.03 \\
9 & $6.70 \times 10^{-11}$ & $5.94 \times 10^{-15}$ & $8.03 \times 10^{-13}$ & 454.01 \\
10 & $6.44 \times 10^{-12}$ & $3.05 \times 10^{-16}$ & $2.73 \times 10^{-14}$ & 743.12 \\
\hline
\end{tabular}


Table 4 Comparison of the values of the of skin friction coefficient for various values of $\mathrm{Mn}$ and $S$ with $A=2, \operatorname{Pr}=\mathrm{Le}=\mathrm{Nb}=1, \theta_{r} \rightarrow \infty$, $\varepsilon_{1}=\varepsilon_{2}=\beta=\gamma=N t=0$.

\begin{tabular}{llcllll}
\hline Mn & $S$ & $\begin{array}{l}\text { Hashmi et al. } \\
\text { (Hashmi et al. 2012) }\end{array}$ & Present Study & & \multicolumn{1}{c}{$\begin{array}{c}\text { CPU time } \\
\text { in seconds }\end{array}$} \\
\hline 0 & 1 & 7.53316579 & 7.533166134027173 & 0.9677134841537185 & $1.734689146770528 \times 10^{-7}$ & 12.0019918 \\
2 & & 8.26387231 & 8.263872005406636 & 0.9704415447020044 & $1.803753433567724 \times 10^{-7}$ & 11.4906528 \\
3 & & 9.09732572 & 9.097325884047699 & 0.9714084422981315 & $2.017660259031556 \times 10^{-7}$ & 11.3115338 \\
5 & & 11.3492890 & 11.3490790688376334 & 0.9671141942979257 & $3.832529114797568 \times 10^{-7}$ & 12.2261407 \\
1 & 0.1 & 8.97552394 & 8.975523936918258 & 0.6586335149025293 & $3.901356871103989 \times 10^{-6}$ & 11.6837806 \\
& 0.5 & 8.34924578 & 8.34924579267211 & 0.8848994230900776 & $5.175581204948535 \times 10^{-7}$ & 11.4095983 \\
& 1 & 7.72194601 & 7.721945958968551 & 0.9686906697036372 & $1.753316413825429 \times 10^{-7}$ & 11.1624343 \\
& & 6.94077326 & 6.940264738765628 & 0.7930138508564271 & $1.820417866243763 \times 10^{-3}$ & 11.1854494 \\
\hline
\end{tabular}

be identical to the results of Das et al. (2016) when $\gamma=0$. In the case of suction, temperature of the fluid decreases as $\gamma$ increases when $\eta \leq 0.74$ and for injection, the trend is reverse when $\eta \geq 0.34$. The influence of the $\operatorname{Pr}$ on $\theta(\eta)$ is displayed in Fig. 3c. It is worth mentioning here that, from the experimental studies it has been noted that at $20{ }^{\circ} \mathrm{C}$, the Prandtl number for air is 0.72 ; at $300{ }^{\circ} \mathrm{C}$, the Prandtl number for water is 1.09 ; at $40{ }^{\circ} \mathrm{C}$, the Prandtl number for ammonia is 2.0; and at $417{ }^{\circ} \mathrm{C}$, the Prandtl number for molten salt is 5.09 (see Tables 4, 5, and 6). Physically, $\operatorname{Pr}<$ $<1$ means high thermal conductivity but low viscosity, while $\operatorname{Pr}>>1$ corresponding to high-viscosity oils (see Kothandaraman and Subramanyan (2014)). Rapid increase in temperature profile is recorded for decreasing Pr, while the thermal boundary layer thickness decreases with increasing values of $\operatorname{Pr}$ (as evident from Table 7). This is due to fluids with higher values of Pr possess a large heat capacity and hence intensifies the heat transfer which leads to a fall in the rate of heat transfer; in addition to this, the assumption of temperature-dependent thermal conductivity suggests a reduction in the magnitude of the velocity by a quantity $\frac{\partial}{\partial r}\left(\lambda(T) \frac{\partial T}{\partial r}\right)+\frac{\partial}{\partial z}\left(\lambda(T) \frac{\partial T}{\partial z}\right)+\lambda(T) \frac{1}{r} \frac{\partial T}{\partial r}$ which can be seen in Eq. (4). Therefore, the rate of cooling is much faster for the coolant material having small values for the thermal conductivity. Opposite behavior of $\theta(\eta)$ is observed in the case of $\varepsilon_{1}$. Figure $3 \mathrm{~d}$ reflects the effects of suction and injection for increasing values of $N t$ and $N b$ on $\theta(\eta)$. The increase in both $N t$ and $N b$ leads increase in $\theta(\eta)$ for suction and for injection opposite nature is observed. The behavior of concentration profile (nanoparticle volume distribution) $\phi(\eta)$ is demonstrated in Fig. 4a, b. Figure $4 \mathrm{a}$ shows the effect of $N t$ and $N b$ on $\phi(\eta)$. Both $N t$ and $N b$ exerts opposite effects on $\phi(\eta)$. Increase in $N t$ results in a decrease in $\phi(\eta)$, this results is due to a larger mass flux at the lower disk. The effect of $L e$ and $\varepsilon_{2}$ on $\phi(\eta)$ is discussed in Fig. 4b. The increase in $\varepsilon_{2}$ results in an increase in concentration and the opposite results are found in the case of Le. Figure $5 \mathrm{a}-\mathrm{c}$ presents the threedimensional plot of the velocity components. These plots exhibit similar results as those of $f^{\prime}(\eta)$.

In Table 7 , we present the results of $f^{\prime \prime}(1), \theta^{\prime}(1)$, and $\phi^{\prime}(1)$ for several sets of values of the physical

Table 5 Comparison of the values of the local Nusselt number for various values of $\mathrm{Nb}$ and $\mathrm{Nt}$ with $A=2, \mathrm{Mn}=\operatorname{Pr}=\mathrm{S}=\mathrm{Le}=$ $1, \theta_{r} \rightarrow \infty, \varepsilon_{1}=\varepsilon_{2}=\beta=\gamma=0$

\begin{tabular}{|c|c|c|c|c|c|c|c|}
\hline \multirow[t]{2}{*}{$\mathrm{Nb}$} & \multirow[t]{2}{*}{$\mathrm{Nt}$} & \multirow{2}{*}{$\begin{array}{l}\text { Hashmi et al. } \\
\text { (2012) }\end{array}$} & \multirow[t]{2}{*}{ Das et al.(2016) } & \multicolumn{3}{|l|}{ Present Study } & \multirow{2}{*}{$\begin{array}{l}\text { CPU time of } \\
\text { the system } \\
\text { in seconds }\end{array}$} \\
\hline & & & & $\overline{-\theta^{\prime}(1)}$ & $-h_{\theta}$ & $E_{15}^{\theta}$ & \\
\hline 0.1 & 0.1 & 0.52628540 & 0.526285397692707 & 0.5262854795861431 & 0.908516 & $1.412748795457583 \times 10^{-11}$ & 54.439 \\
\hline 0.5 & & 0.63433253 & 0.526285397692707 & 0.6343325523545158 & 0.914084 & $1.52497172481667 \times 10^{-13}$ & 54.525 \\
\hline 1.0 & & 0.78636385 & 0.634332530012476 & 0.7863638216341705 & 0.928943 & $9.805935149902197 \times 10^{-13}$ & 54.009 \\
\hline 1.5 & & 0.95569955 & 0.955699547716439 & 0.9556995220292246 & 0.918411 & $7.022421405151564 \times 10^{-12}$ & 54.625 \\
\hline \multirow[t]{4}{*}{1.5} & 0.5 & 1.17682119 & 1.176821184883260 & 1.1768208205076784 & 0.956179 & $2.358155300119884 \times 10^{-10}$ & 53.940 \\
\hline & 1 & 1.48581207 & 1.485811936635642 & 1.4858197859422315 & 1.017842 & $1.217973748574313 \times 10^{-8}$ & 53.585 \\
\hline & 1.5 & 1.82305276 & 1.823053529110100 & 1.8231897567384212 & 0.953137 & $1.724206185011289 \times 10^{-6}$ & 54.439 \\
\hline & 2 & 2.17915991 & 2.179227931099257 & 2.1772753199939645 & 0.817733 & $7.893665960448466 \times 10^{-4}$ & 57.834 \\
\hline
\end{tabular}


Table 6 Comparison of the values of the local Sherwood number for various values of $\mathrm{Nb}$ and $\mathrm{Nt}$ with $A=2, \mathrm{Mn}=\mathrm{Pr}=\mathrm{S}=\mathrm{Le}=$ $1, \theta_{r} \rightarrow \infty, \varepsilon_{1}=\varepsilon_{2}=\beta=\gamma=0$.

\begin{tabular}{llllllll}
\hline $\mathrm{Nb}$ & Nt & $\begin{array}{l}\text { Hashmi et al. } \\
(2012)\end{array}$ & Das et al.(2016) & Present study & & & $\begin{array}{c}\text { CPU time of } \\
\text { the system } \\
\text { in seconds }\end{array}$ \\
\hline 0.1 & 0.1 & 0.86604666 & 0.866046665141329 & 0.8660467842530996 & 0.936748 & $2.426680292036448 \times 10^{-10}$ & 54.439 \\
0.5 & & 0.53012814 & 0.530128143896286 & 0.5301281821145534 & 0.928890 & $9.992908438598528 \times 10^{-13}$ & 54.525 \\
1.0 & & 0.48603919 & 0.486039186120291 & 0.48603915346137855 & 0.891607 & $4.403963236292989 \times 10^{-13}$ & 54.009 \\
1.5 & & 0.46986157 & 0.469861566526085 & 0.4698615495700593 & 0.884253 & $3.657227369041722 \times 10^{-13}$ & 54.625 \\
1.5 & 0.5 & 0.40180718 & 0.401807177532398 & 0.40180541220583815 & 0.908420 & $2.420566500000295 \times 10^{-10}$ & 53.940 \\
& 1 & 0.12619334 & 0.126193335885242 & 0.12617433001495504 & 0.949699 & $2.832474925670632 \times 10^{-8}$ & 53.585 \\
& 1.5 & 0.39083080 & 0.390839865635371 & 0.3900777099943474 & 0.865141 & $6.281273402797455 \times 10^{-6}$ & 54.439 \\
& 2 & 1.16777723 & 1.16800852390237 & 1.1587904533044613 & 0.912246 & $3.5954596655078387 \times 10^{-4}$ & 57.834 \\
\hline
\end{tabular}
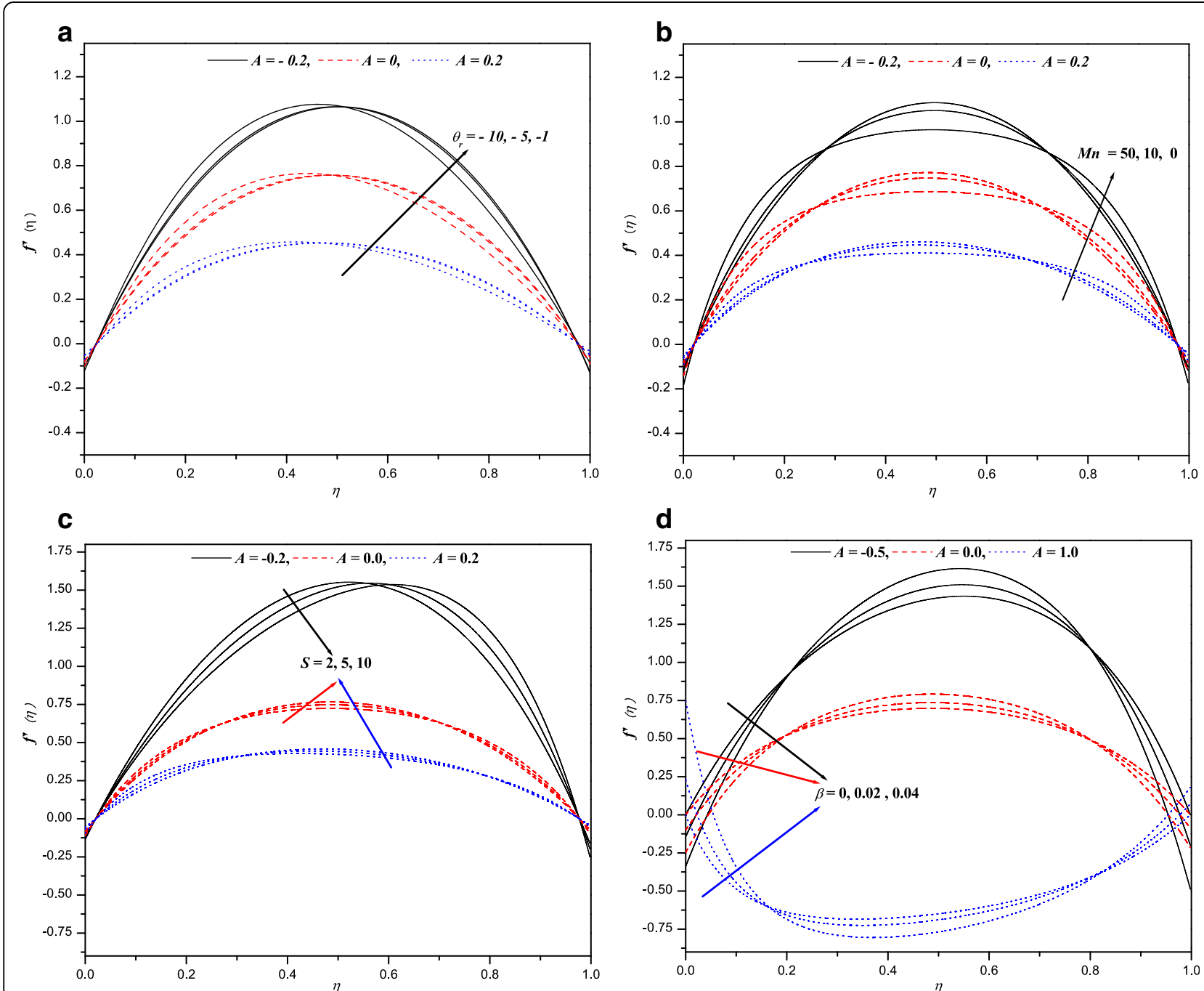

Fig. 2 a Velocity profiles for different values of $\theta_{r}$ and $A$ with $\operatorname{Pr}=0.72, L e=0.66, S=2, \beta=0.02, \gamma=0.1, \mathrm{Mn}=10, \varepsilon_{1}=\varepsilon_{2}=0.2, \mathrm{Nb}=0.2, \mathrm{Nt}=0.2$. b Velocity profiles for different values of $\mathrm{Mn}$ and $\mathrm{A}$ with $\operatorname{Pr}=0.72$, Le $=0.66, \mathrm{~S}=2, \beta=0.02, \gamma=0.1, \varepsilon_{1}=\varepsilon_{2}=0.2, \theta_{r^{-1}}=-5, \mathrm{Nb}=0.2$, $\mathrm{Nt}=0.2$. c Velocity profiles for different values of $S$ and $A$ with $\operatorname{Pr}=0.72$, Le $=0.66, \theta_{r}=-5.0, \mathrm{Mn}=2.0, \varepsilon_{1}=\varepsilon_{2}=0.2, \mathrm{Nb}=0.1, \mathrm{Nt}=0.1, \gamma=.01, \beta=0.02$. d Velocity profiles for different values of $\beta$ and $A$ with $\operatorname{Pr}=0.72$, Le $=0.66, \theta_{r}=-5, M n=10, \varepsilon_{1}=\varepsilon_{2}=0.2, N b=0.2, N t=0.2, \gamma=0, S=2.0$ 

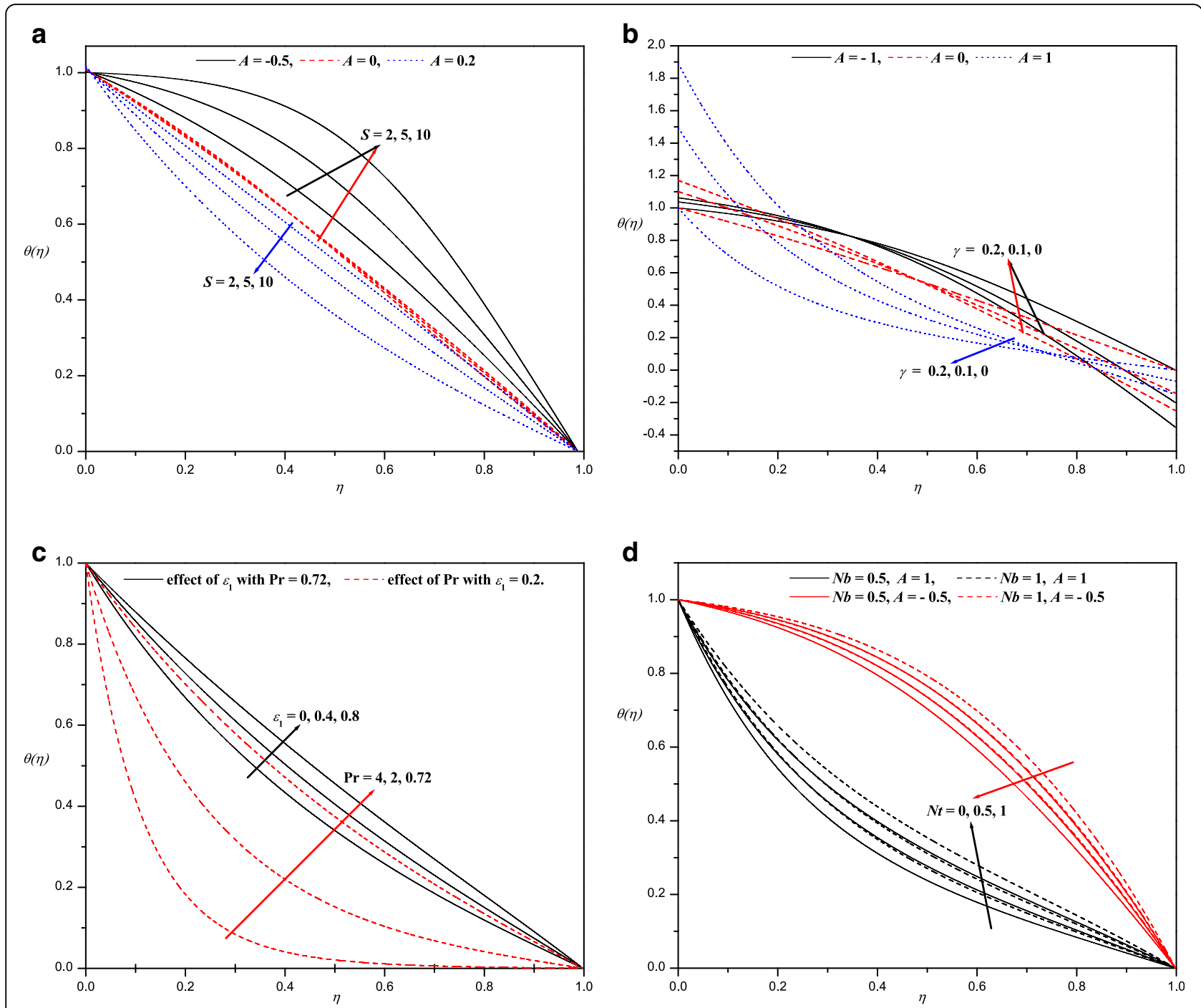

Fig. 3 a Temperature profiles for different values of $S$ and $A$ with $\operatorname{Pr}=0.72$, Le $=0.66, \beta=0.02, \gamma=0.01, M n=10, \varepsilon_{1}=\varepsilon_{2}=0.2, \theta_{r^{-1}}=-5, N b=0.1, N t=0.1$. b Temperature for different values of $\gamma$ and $A$ with $\operatorname{Pr}=0.72$, Le $=0.66, \beta=0.02, S=4, M n=10, \varepsilon_{1}=\varepsilon_{2}=0.2, \theta_{r^{-1}}=-5, N b=N t=0.1$. c Temperature profiles for different values of $\varepsilon_{1}$ and $\operatorname{Pr}$ with $\mathrm{Le}=0.66, S=10, \beta=0.02, \gamma=0.01, \varepsilon_{2}=0.1, A=0.2, \theta_{r^{-1}}=-5, \mathrm{Mn}=10 \mathbf{d}$ Temperature profiles for different values of $\mathrm{Nb}$ and Nt with $\operatorname{Pr}=0.72$, Le $=0.66, \beta=0.02, \gamma=0.01, \varepsilon_{1}=\varepsilon_{2}=0.2, \theta_{r^{1}}=-5, \mathrm{Mn}=10, S=4$

parameters. Increase in the magnetic parameter reduces the skin friction but increases the Nusselt number as well as the Sherwood number. Furthermore, an increase in the variable thermal conductivity parameter and the variable species diffusivity parameter results in an increase in the Nusselt number and the Sherwood number.

\section{Conclusions}

In this paper, an analytical technique is used to solve the mathematical model of MHD squeeze flow of nanofluid between parallel disks. This analysis gives unified results for the parameters $\mathrm{Mn}, S, \mathrm{Nt}$, and $\mathrm{Nb}$, from which one can obtain the results for the special cases of Hashmi et al.
(2012) and Das et al. (2016). The effects of temperaturedependent thermo-physical properties are significant on the flow field. For higher values of the fluid viscosity parameter, the velocity field increases near the walls. However, the transpiration effects are dominant and exhibit the crossflow behavior as well as the dual behavior. The temperature and the concentration fields are respectively the increasing functions of the variable thermal conductivity and the variable species diffusivity parameters.

\section{Nomenclature}

$A$ suction/injection parameter a constant in Eq. (6)

$C$ nanoparticle volumetric fraction 
Table 7 Values of skin friction, Nusselt number, and Sherwood number for different physical parameters with $\gamma=\beta=0.1, \mathrm{Nt}=\mathrm{Nb}=$ $0.1, S=0.1, A=0.01$.

\begin{tabular}{|c|c|c|c|c|c|c|c|c|c|c|c|c|c|c|c|}
\hline Pr & Le & $\varepsilon_{2}$ & $\varepsilon_{1}$ & $\theta_{r}$ & $\mathrm{Mn}$ & $-f^{\prime}(1)$ & $-h_{f}$ & $E_{10}^{f}$ & $-\theta^{\prime}(1)$ & $-h_{\theta}$ & $E_{10}^{\theta}$ & $-\phi^{\prime}(1)$ & $-h_{\phi}$ & $E_{10}^{\phi}$ & CPU time \\
\hline \multirow[t]{5}{*}{6.2} & 1 & 0.1 & 0.1 & -10 & 0.5 & 6.93724 & 0.521876 & $1.85 \times 10^{-5}$ & 2.56836 & 0.795575 & $3.93 \times 10^{-6}$ & -0.20702 & 0.816672 & $6.56 \times 10^{-5}$ & 452.31 \\
\hline & & & & & 1 & 7.16163 & 0.529837 & $1.90 \times 10^{-5}$ & 2.56728 & 0.795370 & $3.87 \times 10^{-6}$ & -0.20606 & 0.816681 & $6.49 \times 10^{-5}$ & 417.61 \\
\hline & & & & & 1.5 & 7.54951 & 0.540578 & $2.20 \times 10^{-5}$ & 2.56541 & 0.794987 & $3.77 \times 10^{-6}$ & -0.20439 & 0.816682 & $6.37 \times 10^{-5}$ & 466.91 \\
\hline & & & & & 2 & 8.12409 & 0.551879 & $2.94 \times 10^{-5}$ & 2.56262 & 0.794530 & $3.16 \times 10^{-6}$ & -0.20191 & 0.816656 & $6.21 \times 10^{-5}$ & 415.70 \\
\hline & & & & & 2.5 & 8.92326 & 0.561811 & $4.11 \times 10^{-5}$ & 2.55874 & 0.793334 & $3.42 \times 10^{-6}$ & -0.19845 & 0.816579 & $5.99 \times 10^{-5}$ & 417.18 \\
\hline \multirow[t]{3}{*}{6.2} & 1 & 0.1 & 0.1 & -10 & 0.1 & 3.23547 & 0.539759 & $3.88 \times 10^{-6}$ & 2.61368 & 0.800566 & $4.60 \times 10^{-6}$ & -0.24769 & 0.820601 & $7.36 \times 10^{-5}$ & 445.34 \\
\hline & & & & -5 & & 6.37108 & 0.796477 & $1.40 \times 10^{-4}$ & 2.57160 & 0.796836 & $4.08 \times 10^{-6}$ & -0.20998 & 0.817371 & $6.64 \times 10^{-5}$ & 404.28 \\
\hline & & & & -1 & & 3.66322 & 0.344926 & $4.32 \times 10^{-2}$ & 2.59901 & 0.400879 & $1.80 \times 10^{-4}$ & -0.23434 & 0.538266 & $3.87 \times 10^{-4}$ & 377.96 \\
\hline \multirow[t]{4}{*}{6.2} & 1 & 0.1 & 0 & -10 & 0.1 & 6.88538 & 0.83426 & $2.12 \times 10^{-6}$ & 4.37052 & 0.753998 & $2.89 \times 10^{-6}$ & -0.05358 & 0.838724 & $5.27 \times 10^{-6}$ & 413.24 \\
\hline & & & 0.2 & & & 6.84778 & 0.563282 & $1.20 \times 10^{-5}$ & 3.29095 & 0.747359 & $7.96 \times 10^{-5}$ & -0.38818 & 0.772511 & $2.83 \times 10^{-4}$ & 416.86 \\
\hline & & & 0.4 & & & 6.80107 & 0.690673 & $6.36 \times 10^{-4}$ & 2.76736 & 0.689505 & $4.11 \times 10^{-4}$ & -0.84408 & 0.694220 & $7.80 \times 10^{-4}$ & 416.80 \\
\hline & & & 0.8 & & & 6.66595 & 0.605364 & 0.602742 & 2.40018 & 0.386541 & 4.20245 & 1.00077 & 0.003287 & $1.63 \times 10^{-4}$ & 536.38 \\
\hline \multirow[t]{4}{*}{6.2} & 1 & 0 & 0.1 & -10 & 0.1 & 6.87282 & 0.817156 & $2.97 \times 10^{-5}$ & 2.53070 & 0.787063 & $1.65 \times 10^{-6}$ & -0.22122 & 0.827749 & $4.33 \times 10^{-5}$ & 407.73 \\
\hline & & 0.2 & & & & 6.86217 & 0.528059 & $1.83 \times 10^{-5}$ & 2.60736 & 0.795988 & $8.99 \times 10^{-6}$ & -0.19379 & 0.805701 & $1.08 \times 10^{-4}$ & 461.73 \\
\hline & & 0.4 & & & & 6.85327 & 0.780916 & $1.10 \times 10^{-4}$ & 2.68649 & 0.785656 & $3.00 \times 10^{-5}$ & -0.16792 & 0.782738 & $3.30 \times 10^{-4}$ & 384.13 \\
\hline & & 0.8 & & & & 6.83347 & 0.580338 & $2.35 \times 10^{-5}$ & 2.85208 & 0.739950 & $1.48 \times 10^{-4}$ & -0.12115 & 0.716450 & $3.26 \times 10^{-3}$ & 416.60 \\
\hline \multirow[t]{4}{*}{6.2} & 1 & 0.1 & 0.1 & -10 & 0.1 & 6.86664 & 0.519571 & $1.84 \times 10^{-5}$ & 2.56923 & 0.795649 & $3.95 \times 10^{-6}$ & -0.20845 & 0.816398 & $6.51 \times 10^{-5}$ & 429.74 \\
\hline & 5.0 & & & & & 6.86634 & 0.522037 & $1.71 \times 10^{-5}$ & 2.57158 & 0.795701 & $3.95 \times 10^{-6}$ & -0.21346 & 0.815193 & $6.23 \times 10^{-5}$ & 444.22 \\
\hline & 10.0 & & & & & 6.86703 & 0.806771 & $4.15 \times 10^{-5}$ & 2.57445 & 0.795678 & $3.96 \times 10^{-6}$ & -0.21969 & 0.813673 & $5.88 \times 10^{-5}$ & 435.78 \\
\hline & 25.0 & & & & & 6.86487 & 0.535357 & $1.18 \times 10^{-5}$ & 2.58273 & 0.795091 & $4.05 \times 10^{-6}$ & -0.23816 & 0.809001 & $4.96 \times 10^{-5}$ & 436.47 \\
\hline 0.72 & 1 & 0.1 & 0.1 & -10 & 0.1 & 7.02711 & 0.910736 & $4.87 \times 10^{-15}$ & 1.43830 & 0.913630 & $2.82 \times 10^{-16}$ & 0.86420 & 0.918855 & $2.80 \times 10^{-14}$ & 380.47 \\
\hline 1.09 & & & & & & 7.01781 & 0.896013 & $8.61 \times 10^{-14}$ & 1.49661 & 0.908669 & $2.18 \times 10^{-14}$ & 0.80733 & 0.905835 & $6.45 \times 10^{-13}$ & 391.07 \\
\hline 2.0 & & & & & & 6.99425 & 0.869605 & $2.11 \times 10^{-11}$ & 1.64904 & 0.830756 & $2.05 \times 10^{-11}$ & 0.65997 & 0.877078 & $1.20 \times 10^{-10}$ & 848.27 \\
\hline 5.09 & & & & & & 0.90495 & 0.826361 & $2.89 \times 10^{-6}$ & 2.28346 & 0.796751 & $2.40 \times 10^{-7}$ & 0.05966 & 0.832669 & $4.16 \times 10^{-6}$ & 552.53 \\
\hline 6.2 & & & & & & 6.86798 & 0.809634 & $4.61 \times 10^{-5}$ & 2.56870 & 0.795627 & $3.95 \times 10^{-6}$ & -0.20732 & 0.816668 & $6.58 \times 10^{-5}$ & 534.81 \\
\hline
\end{tabular}

$C_{w}$ nanoparticle concentration at the lower disk $T$ temperature (K)

$T_{r}$ constant in Eq. (6)

$T_{w}$ temperature at the lower disk (K)

$T_{\infty}$ ambient temperature (K)

$T_{m}$ mean fluid temperature (K)

$\Delta T$ temperature difference $(\mathrm{K})$

$D_{T}$ thermophoretic diffusion coefficient ( $\mathrm{kg} / \mathrm{ms} \mathrm{K}$ )

$D_{B \infty}$ Brownian diffusion coefficient $(\mathrm{kg} / \mathrm{ms})$

$B_{0}$ uniform magnetic field (Tesla)

$C_{p}$ specific heat at constant pressure $(\mathrm{J} / \mathrm{kg} \mathrm{K})$

$C_{f r}$ skin friction

$h(t)$ variable distance $=H(1-\alpha t)^{1 / 2}$

$K(T)$ temperature dependent thermal conductivity

(W/m K)

$K_{\infty}$ thermal conductivity of the fluid far away from the sheet $(\mathrm{W} / \mathrm{m} \mathrm{K})$

Le Lewis number

$M n$ magnetic parameter
$\mathrm{Nb}$ Brownian motion parameter

$N t$ thermophoresis parameter

$N_{u r}$ reduced Nusselt number

Pr Prandtl number

$\mathrm{Re}_{\mathrm{x}}$ local squeeze Reynolds number

$S_{h r}$ reduced Sherwood number

$S$ squeezing parameter

$r, u$, and $w$ radial and axial velocities $(\mathrm{m} / \mathrm{s})$

\section{Greek symbols}

$\alpha$ characteristic parameter

$\zeta$ constant defined in equation (6)

$\nu_{\infty}$ kinematic viscosity away from the sheet $\left(\mathrm{kg} / \mathrm{m}^{3}\right)$

$\rho_{\infty}$ constant fluid density $\left(\mathrm{kg} / \mathrm{m}^{3}\right)$

$\rho_{f}$ density of the fluid $\left(\mathrm{kg} / \mathrm{m}^{3}\right)$

$\sigma$ electric conductivity

$\varepsilon_{1}$ variable thermal conductivity parameter

$\varepsilon_{2}$ variable species diffusivity parameter $\left(\mathrm{m}^{2} / \mathrm{s}\right)$

$\eta$ similarity variables 


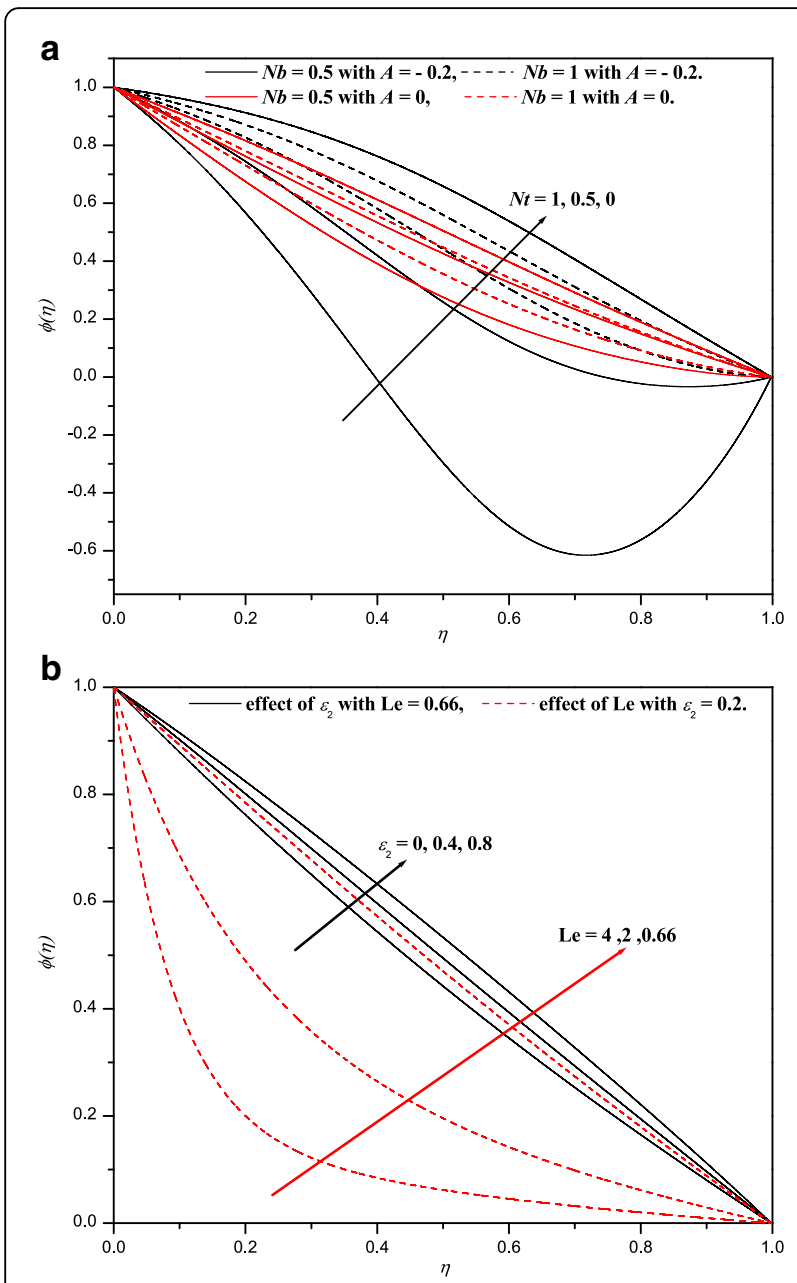

Fig. 4 a Concentration profiles for different values of $\mathrm{Nb}$ and $\mathrm{Nt}$ with $\operatorname{Pr}=0.72$, Le $=0.66, \beta=0.02, \gamma=0.01, \varepsilon_{1}=\varepsilon_{2}=0.1, \theta_{r^{-1}}=-5, \mathrm{Mn}=10.0$, $S=10$. $\mathbf{b}$ Concentration profiles for different values of $\varepsilon_{2}$ and Le with $\operatorname{Pr}=0.72, S=10, \beta=0.02, \gamma=0, \varepsilon_{1}=0.2, A=0.2, \theta_{r^{1}}=-5, M n=10$

$\theta$ dimensionless temperature $\phi$ dimensionless concentration $\theta_{r}$ fluid viscosity parameter $\mu$ dynamic viscosity ( $\mathrm{Pa} \mathrm{s}$ ) $\mu_{h}$ fluid viscosity of the fluid at the upper disk (Pa s)

$k_{h}$ thermal conductivity of the fluid at the upper disk

$D_{\mathrm{Bh}}$ species diffusivity/Brownian diffusion coefficient of the fluid at the upper disk

$\mu_{\infty}$ constant value of dynamic viscosity (Pa s)

$\tau$ ratio between the effective heat capacity of the nanoparticle material and heat capacity of the fluid $\tau_{w}$ wall shear stress $\psi$ stream function $\beta$ velocity slip parameter $\gamma$ thermal slip parameter

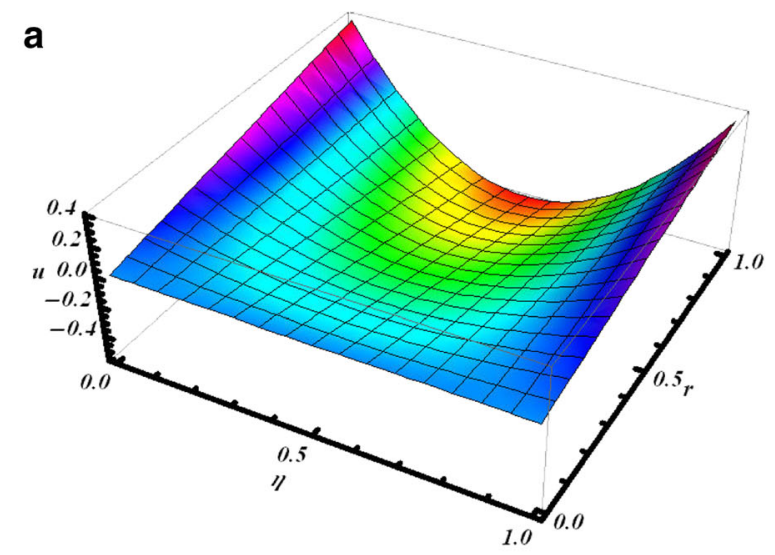

b

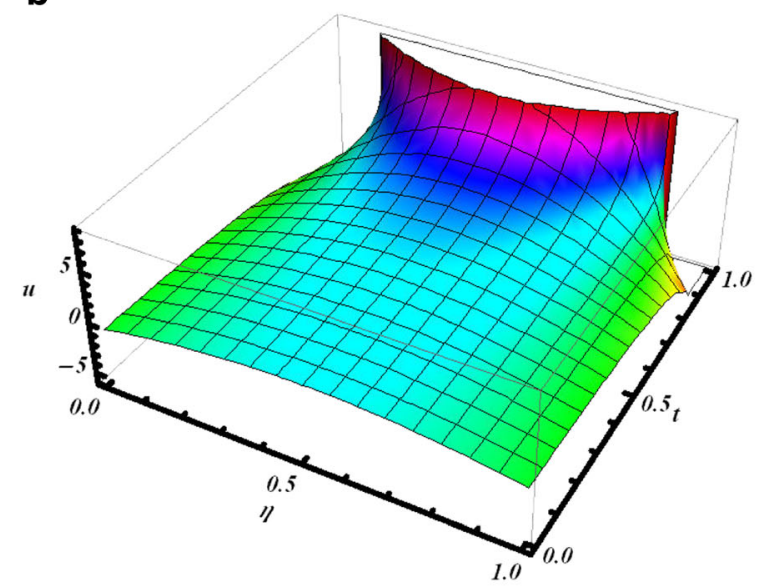

C

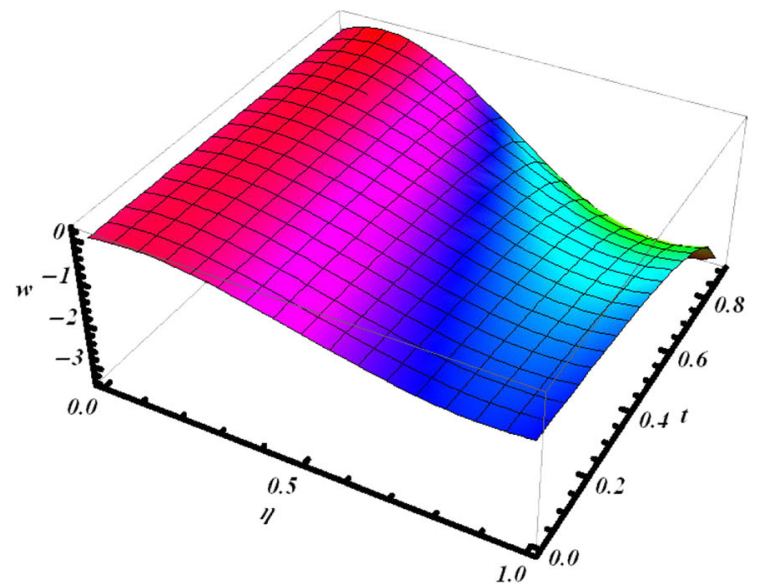

Fig. 5 a 3D plot of $u$ with $\eta$ and $r$. b 3D plot of $u$ with $\eta$ and $t . \mathbf{c} 3 \mathrm{D}$ plot of $w$ with $\eta$ and $t$

\section{Subscripts}

$\infty$ condition at infinity $w$ condition at the wall ' differentiation with respect to $\eta$ 


\section{Authors' contributions}

All authors read and approved the final manuscript.

\section{Competing interests}

The authors declare that they have no competing interests.

\section{Author details}

1Department of Mathematics, University of Central Florida, Orlando, FL 32816, USA. 'Department of Mathematics, VSK University, Vinayaka Nagar, Ballari 583 105, Karnataka, India. ${ }^{3}$ Department of Mechanical Engineering, The University of Hong Kong, Pokfulam, Hong Kong.

Received: 5 December 2016 Accepted: 15 February 2017

Published online: 09 March 2017

\section{References}

M.J. Stefan: Versuch über die scheinbare Adhäsion, Sitzungsber. - Abt. II, Österr. Akad. Wiss., Math.- Naturwiss. K, 69 (1874) 713-721.

Leider, P. J., \& Bird, R. B. (1974). Squeezing flow between parallel disks. I. Theoretical analysis. Industrial and Engineering Chemistry Fundamentals, 13, 336-341.

Hamza, E. A. (1988). The magnetohydrodynamic squeeze film. Journal of Tribology, 110, 375-377.

Domairry, G., \& Aziz, A. (2009). Approximate analysis of MHD squeeze flow between two parallel disks with suction or injection by homotopy perturbation method. Mathematical Problems in Engineering, 2009, 603916.

Joneidi, A. A., Domairry, G., \& Babaelahi, M. (2010). Effect of mass transfer on a flow in the magnetohydrodynamic squeeze film between two parallel discs with one porous disk. Chemical Engineering Communications, 198, 299-311.

Hayat, T., Yousaf, A., Mustafa, M., \& Obaidat, S. (2012). MHD squeezing flow of second-grade fluid between two parallel disks. International Journal for Numerical Methods in Fluids, 69, 399-410.

Hussain, A., Mohyud-Din, S. T., \& Cheema, T. A. (2012). Analytical and numerical approaches to squeezing flow and heat transfer between two parallel disks with velocity slip and temperature jump. Chinese Physics Letters, 29, 114705.

Shaban, M., Shivanian, E., \& Abbasbandy, S. (2013). Analyzing magnetohydrodynamic squeezing flow between two parallel disks with suction or injection by a new hybrid method based on the Tau method and the homotopy analysis method. European Physical Journal Plus, 128, 1-10.

S.U.S. Choi, J.A. Eastman: Enhancing thermal conductivity of fluids with nanoparticles. Proceedings of the 1995 ASME Int. Mech. Eng. Cong. and Exposition, San Francisco, USA, ASME FED 231/MD 66:99,105, 1995.

Vajravelu, K., Prasad, K. V., Lee, J., Lee, C., Pop, I., \& Van Gorder, R. A. (2011). Convective heat transfer in the flow of viscous Ag-water and Cu-water nanofluids over a stretching surface. International Journal of Thermal Sciences, $50,843-851$

Makinde, O. D., \& Aziz, A. (2011). Boundary layer flow of a nanofluid past a stretching sheet with a convective boundary condition. International Journal of Thermal Sciences, 50, 1326-1332.

Bachok, N., Ishak, A., \& Pop, I. (2012). Unsteady boundary-layer flow and heat transfer of a nanofluid over a permeable stretching/shrinking sheet. International Journal of Heat and Mass Transfer, 55, 2102-2109.

Safaei, M. R., Togun, H., Vafai, K., Kazi, S. N., \& Badarudin, A. (2014). Investigation of heat transfer enhancement in a forward-facing contracting channel using FMWCNT nanofluids. Numerical Heat Transfer Part A, 66, 1321-1340.

Safaei, M. R., Mahian, O., Garoosi, F., Hooman, K., Karimipour, A., Kazi, S. N., \& Gharehkhani, S. (2014). Investigation of micro and nano-sized particle erosion in a $90^{\circ}$ pipe bend using a two-phase discrete phase model. Scientific World Journal, 2014, 740578 .

Goodarzi, M., Safaei, M. R., Vafai, K., Ahmadi, G., Dahari, M., Kazi, S. N., \& Jomhari, N. (2014). Investigation of nanofluid mixed convection in a shallow cavity using a two-phase mixture model. International Journal of Thermal Sciences, 75, 204-220.

Togun, H., Safaei, M. R., Sadri, R., Kazi, S. N., Badarudin, A., Hooman, K., \& Sadeghinezhad, E. (2014). Numerical simulation of laminar to turbulent nanofluid flow and heat transfer over a backward-facing step. Applied Mathematics and Computation, 239, 153-170.

Prasad, K. V., Vajravelu, K., Shivakumara, I. S., Vaidya, H., \& Basha, N. Z. (2016). Flow and heat transfer of a Casson nanofluid over a nonlinear stretching sheet Journal of Nanofluids, 5, 743-752.
Hashmi, M. M., Hayat, T., \& Alsaedi, A. (2012). On the analytic solutions for squeezing flow of nanofluid between parallel disks. Nonlinear Anal Model Control, 17, 418-430.

Das, K., Jana, S., \& Acharya, N. (2016). Slip effects on squeezing flow of nanofluid between two parallel discs. International Journal of Applied Mechanics and Engineering, 21, 5-20.

S.T. Mohyud-Din, S.I. Khan, B. Bin-Mohsin: Velocity and temperature slip effects on squeezing flow of nanofluid between parallel disks in the presence of mixed convection, Neural Comput. Applic., (2016). DOl: 10.1007/s00521-2016-2329-1.

Lai, F. C., \& Kulacki, F. A. (1990). The effect of variable viscosity on convective heat transfer along a vertical surface in a saturated porous medium. International Journal of Heat and Mass Transfer, 33, 1028-1031.

Vajravelu, K., Prasad, K. V., \& Ng, C. O. (2013). Unsteady convective boundary layer flow of a viscous fluid at a vertical surface with variable fluid properties. Nonlinear Anal Real World Applications, 14, 455-464.

Prasad, K. V., Vajravelu, K., \& Vaidya, H. (2016). MHD Casson nanofluid flow and heat transfer at a stretching sheet with variable thickness. Journal of Nanofluids, 5, 423-435.

Vajjha, R. S., \& Das, D. K. (2012). A review and analysis on influence of temperature and concentration of nanofluids on thermophysical properties, heat transfer and pumping power. International Journal of Heat and Mass Transfer, 55, 4063-4078.

Liao, S. (2003). Beyond perturbation: introduction to homotopy analysis method. London: Chapman \& Hall/CRC Press.

Fan, T., \& You, X. (2013). Optimal homotopy analysis method for nonlinear differential equations in the boundary layer. Numerical Algorithms, 62, 337-354

Lawal, A., \& Kalyon, D. M. (1998). Squeezing flaw of viscoplastic fluids subject to wall slip. Polymer Engineering and Science, 38, 1793-1804.

( P Kothandaraman, S Subramanyan. Heat and mass transfer data book, New Age International (P) Ltd., Publishers, 2014).

\section{Submit your manuscript to a SpringerOpen ${ }^{\mathcal{O}}$ journal and benefit from:}

- Convenient online submission

- Rigorous peer review

- Immediate publication on acceptance

- Open access: articles freely available online

- High visibility within the field

- Retaining the copyright to your article

Submit your next manuscript at $\boldsymbol{s p r i n g e r o p e n . c o m ~}$ 